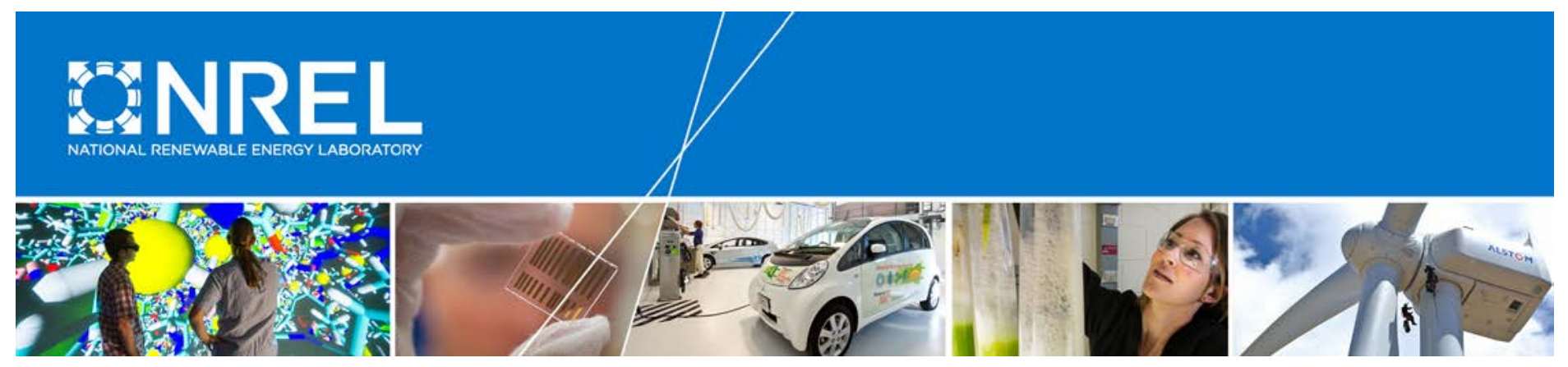

\title{
Energy-Water Microgrid Opportunity Analysis at the University of Arizona's Biosphere 2 Facility
}

Jennifer Daw, Alicen Kandt, Julieta Giraldez, Jordan Macknick, and Kate Anderson National Renewable Energy Laboratory

Neal Armstrong and John Adams University of Arizona

NREL is a national laboratory of the U.S. Department of Energy Office of Energy Efficiency \& Renewable Energy Operated by the Alliance for Sustainable Energy, LLC

This report is available at no cost from the National Renewable Energy Laboratory (NREL) at www.nrel.gov/publications.

Technical Report

NREL/TP-7A40-71294

May 2018

Contract No. DE-AC36-08GO28308 


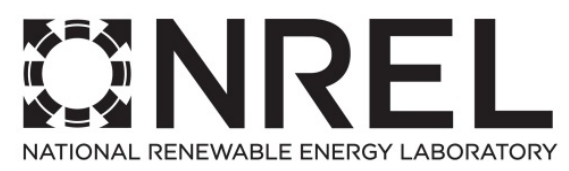

\section{Energy-Water Microgrid Opportunity Analysis at the University of Arizona's Biosphere 2 Facility}

Jennifer Daw, Alicen Kandt, Julieta Giraldez, Jordan Macknick, and Kate Anderson National Renewable Energy Laboratory

Neal Armstrong and John Adams University of Arizona

Prepared under Task No. 066A1601

NREL is a national laboratory of the U.S. Department of Energy Office of Energy Efficiency \& Renewable Energy Operated by the Alliance for Sustainable Energy, LLC

This report is available at no cost from the National Renewable Energy Laboratory (NREL) at www.nrel.gov/publications.

National Renewable Energy Laboratory 15013 Denver West Parkway Golden, CO 80401

303-275-3000 • www.nrel.gov
Technical Report

NREL/TP-7A40-71294

May 2018

Contract No. DE-AC36-08GO28308 


\section{NOTICE}

This report was prepared as an account of work sponsored by an agency of the United States government. Neither the United States government nor any agency thereof, nor any of their employees, makes any warranty, express or implied, or assumes any legal liability or responsibility for the accuracy, completeness, or usefulness of any information, apparatus, product, or process disclosed, or represents that its use would not infringe privately owned rights. Reference herein to any specific commercial product, process, or service by trade name, trademark, manufacturer, or otherwise does not necessarily constitute or imply its endorsement, recommendation, or favoring by the United States government or any agency thereof. The views and opinions of authors expressed herein do not necessarily state or reflect those of the United States government or any agency thereof.

This report is available at no cost from the National Renewable Energy Laboratory (NREL) at www.nrel.gov/publications.

Available electronically at SciTech Connect http:/www.osti.gov/scitech

Available for a processing fee to U.S. Department of Energy and its contractors, in paper, from:

U.S. Department of Energy

Office of Scientific and Technical Information

P.O. Box 62

Oak Ridge, TN 37831-0062

OSTI http://www.osti.gov

Phone: 865.576.8401

Fax: 865.576.5728

Email: reports@osti.gov

Available for sale to the public, in paper, from:

U.S. Department of Commerce

National Technical Information Service

5301 Shawnee Road

Alexandria, VA 22312

NTIS http://www.ntis.gov

Phone: 800.553 .6847 or 703.605 .6000

Fax: 703.605.6900

Email: orders@ntis.gov 


\section{Acknowledgments}

NREL would like to acknowledge the contributions to this study from the University of Arizona researchers and Biosphere 2 staff, including Stan Reynolds, Kelly Potter, Neng Fan, Janet Meiling Roveda, Young-Jun Son, Greg Barron-Gafford, and Nirav Merchant. This work was funded through National Renewable Energy Laboratory internal Laboratory Directed Research and Development funding. The authors would like to thank Dan Olis, Josh Sperling, Mari Shirazi, and Adam Warren for their technical reviews, and Britton Marchese and Molly Putzig for their editorial support. 


\section{List of Acronyms}

$\begin{array}{ll}\text { AHU } & \text { air handling unit } \\ \text { ANSI } & \text { American National Standards Institute } \\ \text { B2 } & \text { Biosphere } 2 \\ \text { DER } & \text { distributed energy resource } \\ \text { gpm } & \text { gallons per minute } \\ \text { HMI } & \text { Human Machine Interface } \\ \text { IEEE } & \text { Institute of Electrical and Electronics Engineers } \\ \text { kWh } & \text { kilowatt-hour } \\ \text { kV } & \text { kilovolt } \\ \text { kVa } & \text { kilovolt-amp } \\ \text { kW } & \text { kilowatt } \\ \text { LCC } & \text { lifecycle cost } \\ \text { MW } & \text { megawatt } \\ \text { NREL } & \text { National Renewable Energy Laboratory } \\ \text { NPV } & \text { net present value } \\ \text { PID } & \text { Proportional Integral Derivative } \\ \text { RE } & \text { renewable energy } \\ \text { REopt } & \text { Renewable Energy Integration and Optimization } \\ \text { RO } & \text { decision support model } \\ \text { SCIP } & \text { reverse osmosis } \\ \text { PV } & \text { San Carlos Irrigation Project } \\ \text { U of A } & \text { solar photovoltaics } \\ \text { VFD } & \text { University of Arizona } \\ \text { V } & \text { variable frequency drive } \\ & \text { volts } \\ & \end{array}$




\section{Executive Summary}

Many industrial facilities, campuses, and cities have been exploring options to achieve reliability and resilience of both energy and water system operations, especially in the context of exposures to diverse types of stresses (e.g., aging infrastructure, extreme weather events, supply chain vulnerabilities) and climate uncertainty. Microgrids have emerged as a promising approach to provide reliable and cost-effective energy services in a variety of decentralized settings. There is also growing recognition that water infrastructure requires substantial energy, and that water operations can be better managed to provide grid services. However, there has been minimal exploration in developing or analyzing integrated, optimized energy-water systems that demonstrate the feasibility and synergies associated with designing and operating energy and water systems in a coordinated framework. Energy-water microgrids-where water infrastructure plays a key role in energy load management, and where the interdependencies of both the water and energy systems are co-optimized — could be a promising solution for a wide range of geographic and economic contexts, such as isolated communities or those lacking reliable, critical infrastructure.

In this study, we use the University of Arizona's Biosphere 2 (B2) facility as a case study for an energy-water microgrid test site, with the potential to catalyze future energy-water system integration research. B2 features both energy and water systems that can operate, or can be modified to operate, either connected to the larger power grid or independent of the grid, providing a suitable location for design and demonstration of an energy-water microgrid. We identified opportunities for energy and water efficiency and estimated the sizes of renewable energy (RE) and storage systems required to meet remaining loads in a microgrid, identified dispatchable loads in the water system, and laid the foundation for an in-depth energy-water microgrid analysis.

Key findings from the study include the following, which are addressed in more detail later in the report:

1. The B2 facility is an ideal energy-water microgrid case study

2. Energy and water efficiency improvements should be made prior to establishing a microgrid at B2

3. A renewable-powered microgrid is feasible at the $\mathrm{B} 2$ facility

4. Collaborative research could further evaluate an energy-water microgrid at the B2 facility.

\section{The B2 facility is an ideal energy-water microgrid case study}

The B2 facility has several unique characteristics to support an energy-water microgrid:

- Large dispatchable electricity and water loads: Dispatchable and flexible energy and water loads provide an important foundation that could allow for co-optimized management of energy and water systems.

- Onsite generation potential from renewable and fossil sources: High quality solar resources would facilitate the use of solar photovoltaic (PV) technologies with battery storage to power an RE-water microgrid with existing conventional generation backups. 
- B2 is microcosm of other potential sites for microgrids: The B2 facility has periodic issues with power reliability and quality from the grid, and thus has a motivation to explore potential islanding of their systems.

- Diverse industrial, commercial, and residential loads: The B2 facility accommodates a range of loads to support research, education, and tours, and insights from an energywater microgrid can be applicable to other campuses with these loads.

- Educational and public outreach focus: The educational and outreach mission of B2 allows lessons learned from microgrids to be widely and effectively disseminated. Further, the B2 facility is an ideal test bed for demonstrating and promoting the viability of highly efficient closed-loop systems that integrate RE, water, and food/land resources.

\section{Opportunities for energy and water efficiency improvements}

We identified single sector opportunities for energy and water efficiency measures that should be implemented prior to establishing an integrated energy-water microgrid at the B2 facility. These measures include:

- Installing variable frequency drives

- Implementing demand-side management strategies

- Reducing B2 facility energy use through efficiency measures

- Implementing more sophisticated Proportional Integral Derivative (PID) controller control loops for equipment

- Dissipating heat more efficiently to shed heat loads

- Ramping cooling/heating load during early and late portion of the day

- Implementing water conservation strategies.

Reducing energy and water use is the first step toward establishing a microgrid at B2. Adopting these measures will ensure optimal use of energy and water resources and right-sizing of the microgrid, including the amount of on-site RE generation and energy storage required to support daily operations.

\section{A renewable-powered energy-water microgrid is feasible at $B 2$}

We modeled a preliminary RE microgrid design for the B2 Energy Center to show the level of RE generation and storage that a 100\% RE-powered microgrid would require to serve the critical load during loss of utility grid. The critical load is assumed to be $35 \%$ of the nominal Energy Center load (Figure ES-1). Remaining load would be reduced through energy efficiency and demand-side management strategies or shed as noncritical during an outage. Excess solar energy generation is used to charge batteries that can meet loads during the night. It was assumed that the existing conventional generation assets would not be used as part of this microgrid. We also conducted an additional evaluation of a microgrid that allowed for a limited use of a diesel generator. 


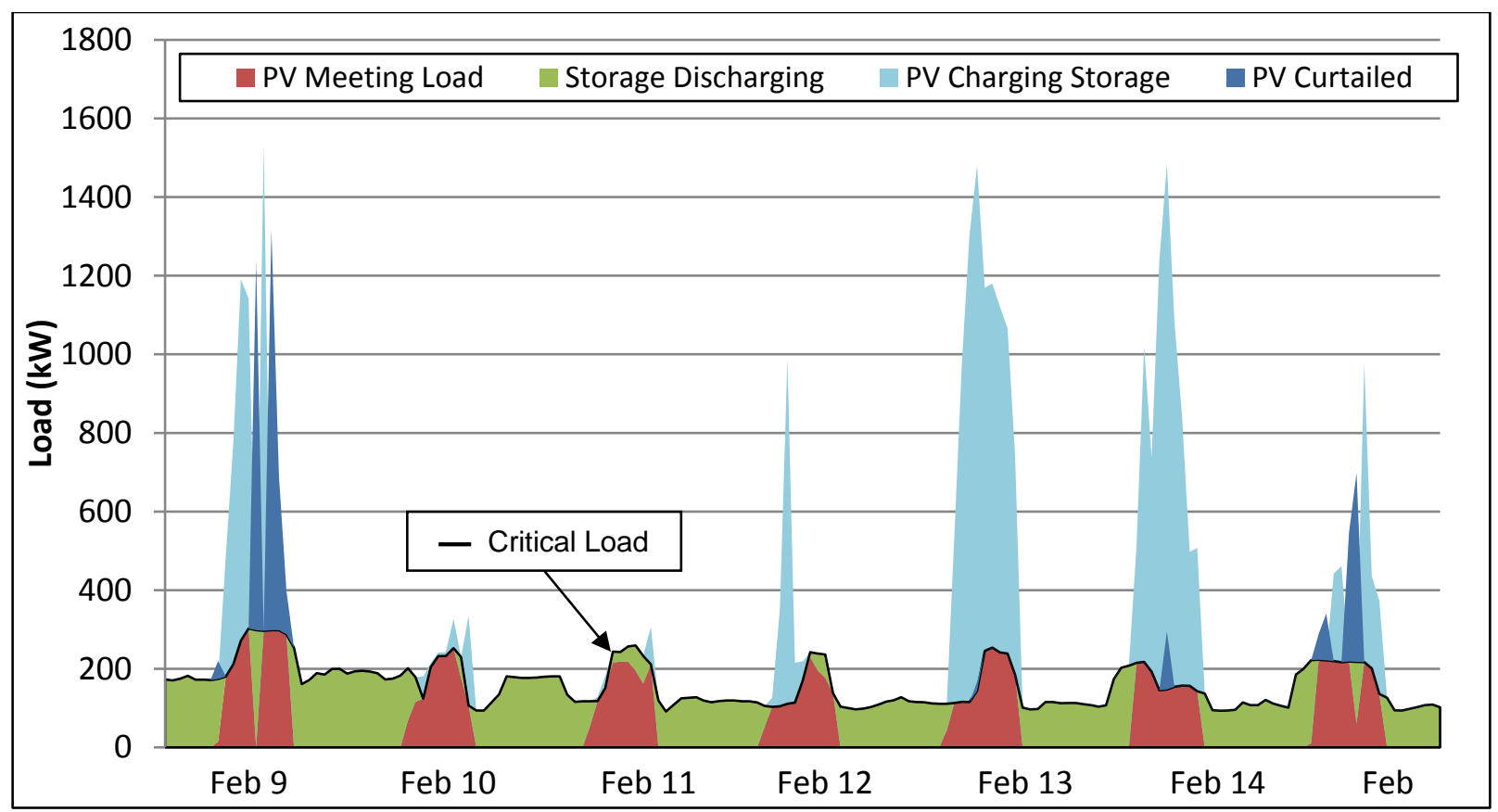

Figure ES-1. PV and storage sustain the critical load in the $100 \%$ renewable energy microgrid

The microgrid system should be designed with a sophisticated supervisory control and data acquisition system to optimize operations of energy consuming infrastructure and support research experiments. A modernized data acquisition and control infrastructure with a microgrid controller capable of controlling both conventional and RE generation sources can:

- Monitor and control distributed energy resources

- Balance supply and demand

- Optimize resources and load

- Transition between operating parallel with the utility and in an electrically islanded state

- Respond to utility or market demand response signals.

\section{Future collaborative research opportunities}

While initial analyses show promising opportunities for an energy-water microgrid at the B2 facility, there remain substantial research gaps and opportunities for collaborative research to more comprehensively understand tradeoffs and configurations of different microgrid designs. To further explore the feasibility of an energy-water microgrid at B2, future efforts may include analyzing the performance of water systems under modified operations (e.g., ramping up and down, modifying pumping and storage schemes, incorporating variable RE generation) at the rates and frequencies needed to characterize the water system's ability to be used as a dispatchable load. Other collaborative opportunities include:

- Economic Analyses: Additional analytical efforts are needed to more fully assess the economic benefits and tradeoffs of an energy-water microgrid at B2, and the potential implications for future microgrid developments in other locations. 
- Controls and Optimization: There is room for improvement in the optimization of B2 operations and in energy and water efficiency through the addition and increased use of controls and automation.

- Water Systems: Water systems at B2 could support microgrid operations by modifying pumping, treatment, and storage practices to provide energy storage and ancillary services by operating as a dispatchable load.

- Cybersecurity and Resilience: Cybersecurity threats remain an understudied field for microgrids, and the B2 facility could serve as a primary test bed for detecting, addressing, and preventing cybersecurity impacts on microgrids.

- Solar Resource Forecasting and Installation Configuration: PV could be used to power the energy-water microgrid, and there are research gaps associated with solar resource forecasting techniques that are necessary for multiple microgrid configurations.

- Partnerships with Regional Electric Utilities: Given the potential for the B2 facility to island itself from the grid but also to generate additional electricity or provide grid services, greater interaction and collaboration with regional electric utilities will be needed to better understand the value of the grid services that B2 could provide. 


\section{Table of Contents}

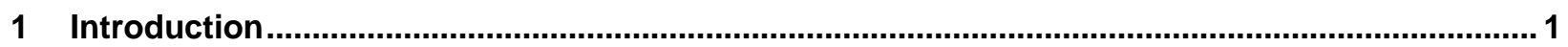

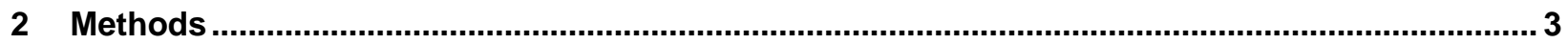

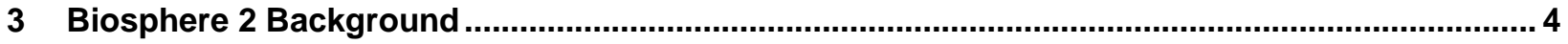

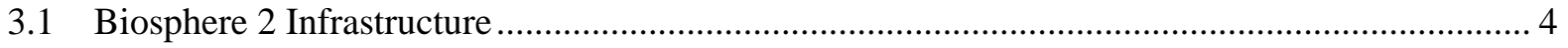

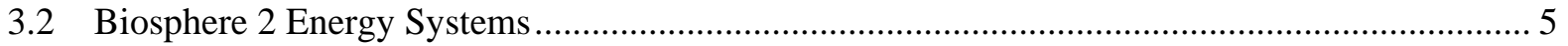

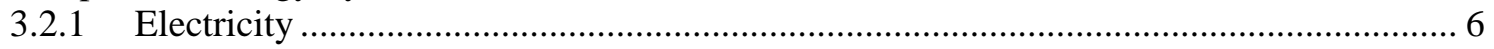

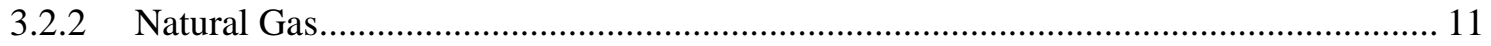

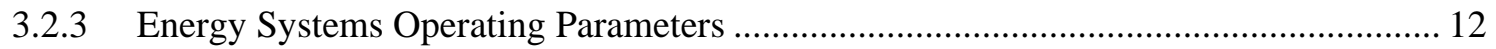

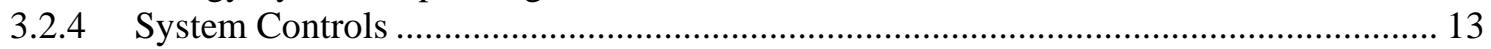

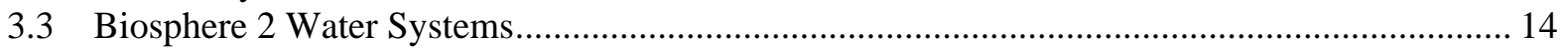

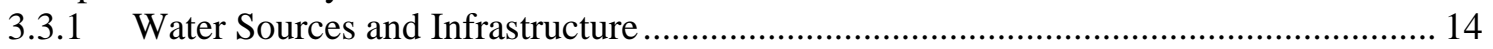

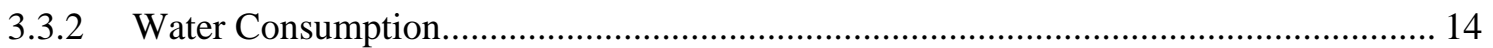

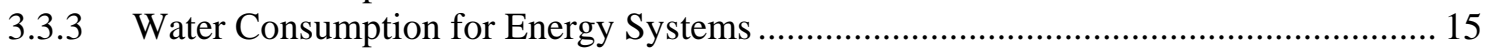

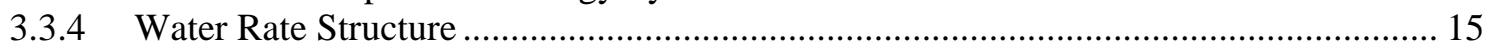

3.3.5 Water System Operating Parameters............................................................................. 16

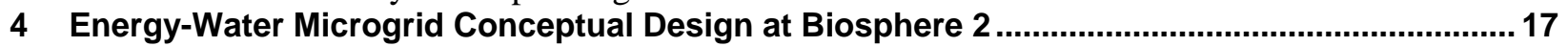

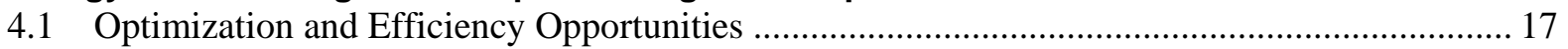

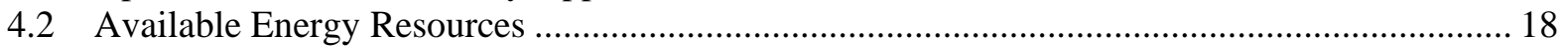

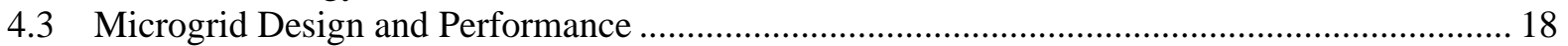

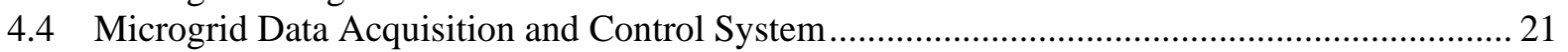

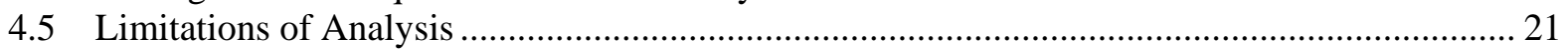

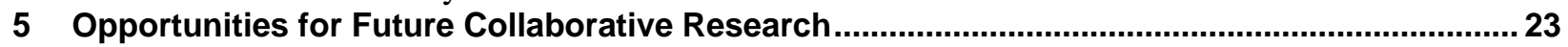

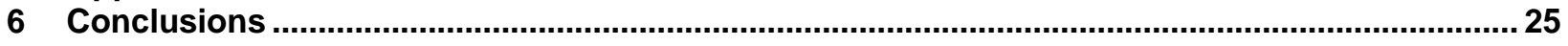

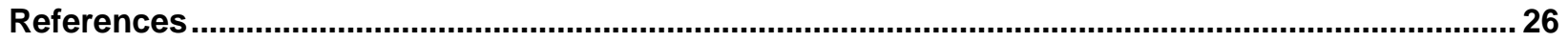




\section{List of Figures}

Figure ES-1. PV and storage sustain the critical load in the $100 \%$ renewable energy microgrid................vii

Figure 1. B2's energy and water infrastructure. Figure from University of Arizona staff ............................ 5

Figure 2. B2's model ecosystems. Figure from University of Arizona staff.............................................. 6

Figure 3. Campus facility map and electrical meter locations. Figure from University of Arizona staff...... 7

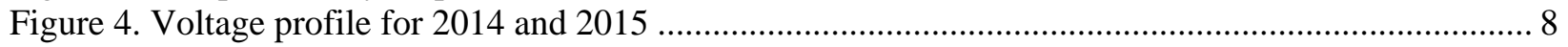

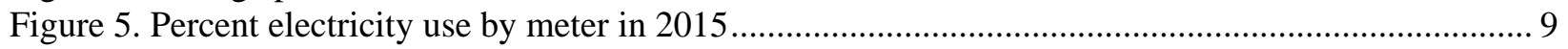

Figure 6. B2 Annual Energy Center usage from 2007-2015 ....................................................... 9

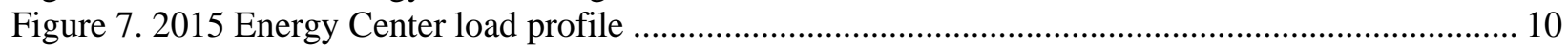

Figure 8. Casita and Visitor Center electricity usage from 2007-2015 ................................................. 10

Figure 9. Annual Well electricity usage from 2007-2015 ..................................................................... 11

Figure 10. Annual natural gas usage from 2007-2015 .......................................................................... 12

Figure 11. April 18, 2012, from 5-10 p.m., Energy Center and B2 load (SCIP) and diesel generator load

Figure 12. Annual water consumption from 2007-2015 .................................................................... 15

Figure 13. Annual makeup water usage from 2007-2015 .................................................................... 15

Figure 14. PV and storage sustain the critical load in the $100 \%$ renewable energy microgrid................... 20

\section{List of Tables}

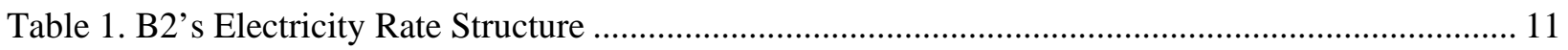

Table 2. Microgrid Modeling Assumptions .......................................................................................... 19

Table 3. Renewable Energy Microgrid System Sizes and Economics .................................................... 19

Table 4. Renewable Energy + Diesel Microgrid System Sizes and Economics ......................................... 21

No table of figures entries found. 


\section{Introduction}

Innovative research related to the intersection of the energy and water sectors has risen rapidly around the world, as understanding of synergies, opportunities, and tradeoffs among these sectors is sought (Bazilian et al. 2011; Hussey and Pittock 2012; Sanders 2015). A driving force in many cases has been the desire for greater reliability and resilience of both energy and water systems operations, especially in the context of climate uncertainty (Watts et al. 2012; Sitzenfrei et al. 2013; Macknick et al. 2016; Amarasinghe et al. 2016; Diao et al. 2016). There has been a clear recognition of the importance of considering energy management and flexibility in decentralized water systems operations to improve resilience (Plappally and Lienhard V 2012; Sanders and Webber 2012; Deng et al. 2013; Piratla and Goverdhanam 2015). At the same time, microgrids have emerged as a promising approach to provide reliable and cost-effective energy services in a variety of decentralized settings (Lasseter and Paigi 2004; Haritza et al. 2016). To date, however, there has been minimal effort invested in conceptualizing or developing integrated, optimized energy-water systems that demonstrate the feasibility and synergies associated with designing and operating energy and water systems in a coordinated framework (Bognar et al. 2012; Hwang et al. 2014; Mbarga et al. 2014; Falco and Webb 2015; Cendoya et al. 2015). These energy-water microgrids could be a promising solution for a wide range of geographic and economic contexts, such as isolated communities or those lacking reliable, critical infrastructure. Operating protocols and demonstrations are necessary to fully understand the benefits and tradeoffs of energywater microgrids.

For the purpose of this study, we define a microgrid as "a group of interconnected loads and distributed energy resources (DERs) within clearly defined electrical boundaries that acts as a single controllable entity with respect to the grid. A microgrid can connect and disconnect from the grid to enable it to operate in both grid-connected and island-mode" (Ton and Smith 2012). Microgrids are typically composed of DERs that can provide independent power to designated critical loads upon loss of their primary source of energy (Lasseter and Paigi 2004). However, a microgrid is distinct from an emergency back-up system in that the microgrid has the capability to operate either grid-connected or islanded. Microgrids are typically managed through a central controller that monitors the system operating parameters, coordinates DER assets, balances and controls loads, and is responsible for disconnection and reconnection of the microgrid to the primary grid. The scale and type of benefits created from microgrids will vary depending on customer and location-specific circumstances, including the thermal and electric demands of interconnected loads, the configuration of the local distribution system, the ability of existing legacy grid infrastructure to meet load growth, the local utility's generation mix, the retail cost of energy, and energy market structure among others. Microgrids have the potential to reduce overall energy costs by reducing energy consumption through on-site energy generation resulting in peak demand reduction. Further, microgrids have the potential to participate in demand-response programs and provide transmission and distribution ancillary services, greater use of renewable generation through advanced control systems, increased power quality, and reduced power interruptions. An energy-water microgrid is a microgrid where water infrastructure plays a key role in energy load management, and where the operations of both the water and energy systems are cooptimized.

The National Renewable Energy Laboratory (NREL) and the University of Arizona (U of A) engaged in collaborative research activities to explore the energy-water nexus and its broader national and international potential in the context of energy-water microgrids. The U of A's Biosphere 2 (B2) facility was identified as a promising case study for an energy-water microgrid test site, with the potential to catalyze future energy-water system integration research. B2 features both energy and water systems that can operate or can be modified to operate either connected to the larger power grid or independent of the grid, providing a suitable location for design and demonstration of an energy-water microgrid. 
In this study, U of A's B2 facility was used as a test case to identify opportunities for energy and water efficiency and to estimate the sizes of renewable energy (RE) and storage systems required to meet remaining loads in a microgrid. To further explore the feasibility of an energy-water microgrid at B2, future efforts may include analyzing the performance of water systems under modified operations (e.g., ramping up and down, modifying pumping and storage schemes, incorporating variable RE generation) at the rates and frequencies needed to characterize the water system's ability to be used as a dispatchable load as an opportunity to provide ancillary services. 


\section{Methods}

The conceptual design and simulation of an energy-water microgrid at the B2 facility was informed by reviewing B2 operations data, on-site visits to evaluate equipment and operating procedures, discussions with B2 staff, and modeling of various microgrid designs of B2 infrastructure.

Historical data on energy and water usage were available from 2007 to mid-year 2016. Energy usage data at the B2 facility are sub-metered and were available at the 15-minute level. Water usage data at the B2 facility were available at the monthly level for four main meters, but not at a sub-metered level.

NREL used the Renewable Energy Integration and Optimization (REopt) modeling platform to develop a conceptual RE microgrid design (Anderson et al. 2017). Formulated as a mixed integer linear program, the REopt model recommends an optimally sized mix of conventional and RE systems, demand management, and energy storage technologies to meet a specified site load (full, critical, etc.); estimates the lifecycle cost associated with implementing and operating those technologies; and provides the costoptimal dispatch strategy for operating them at maximum economic efficiency. For this project, the REopt model was used to evaluate the least-cost method to power the Energy Center's critical loads for the 10-year analysis period ${ }^{1}$ using only RE and storage. This analysis used hourly time steps to ensure the seasonal variation in the load and resource availability over the course of a year was captured by the model. The resulting optimized energy balance for one year was then assumed to exist for all subsequent years in a 10-year analysis period. An estimated electricity cost escalation rate of $0.1 \%$ as well as a discount rate of $3.1 \%$ was used to translate costs in future years to the present. This rate was used to estimate how much energy would cost if B2 continued to purchase from the power utility instead of using solar photovoltaics (PV)/storage. It was assumed that no financial incentives were available to reduce the costs associated with the RE and storage technologies.

\footnotetext{
${ }^{1}$ A 10 -year analysis period was used because of standard University of Arizona contracting requirements, which may negatively impact economic outcomes as compared to a more typical 25-year analysis period.
} 


\section{Biosphere 2 Background}

The B2 facility is a laboratory for controlled scientific studies situated on 40 acres in a remote area outside of Tucson, Arizona. The research conducted at B2 is focused on addressing societal challenges related to water, environmental, and energy management through large-scale physical experimentation in each of its seven model ecosystems (or biomes). These experiments inform the development of computer models that simulate biological, physical, and chemical processes to predict ecosystem response to environmental change. B2 research informs scientists about the next level of experimentation needed to advance understanding of these complex systems, which can be tested against observations in natural systems. B2's support systems, including its physical infrastructure and energy and water systems make it a promising case study for an energy-water microgrid.

\subsection{Biosphere 2 Infrastructure}

The B2 campus includes the B2 research facility building, 28 Casitas (used for visitor lodging), a Visitors' Center, Energy Center, and several small operations buildings. These buildings represent industrial, commercial, and residential spaces that have different energy and water requirements (Figure 1). The support structures (excluding B2) have an area of approximately 300,000 square feet. The B2 building is a 3.14-acre research facility (Figure 2). Its unique glass construction, made up of 6,500 windows, encompasses 7.2 million cubic feet and is 91 feet at its highest point.

B2 was originally constructed in 1986 and U of A took ownership of it in 2007. The facility houses seven model ecosystems, including:

1. A mature rainforest with more than 90 tropical tree species

2. A million-gallon ocean

3. Forested swamps dominated by mangrove trees

4. A subtropical savanna

5. A coastal fog desert

6. Three sloping convergent landscapes (Landscape Evolution Observatory)

7. The greater B2 facility, its campus, and associated buildings and facilities, serving as a 40-acre model city and urban ecosystem.

Each of these ecosystems has specific operating requirements that must be met to satisfy research and human needs, many of which require substantial amounts of energy and water resources. For example, to maintain the rainforest biome, the temperature must be kept between $70^{\circ}$ and $100^{\circ} \mathrm{F}$, and heating units are run at night during some periods of the year to maintain adequate temperatures. This biome also requires regular rainfall, with water provided by B2's on-site reverse osmosis (RO) water treatment system. The ocean biome represents 20\%-30\% of B2's energy loads for heating and cooling and requires makeup water treated by energy intensive RO and ultraviolet disinfection systems. The savanna biome also poses significant energy demands for cooling. 


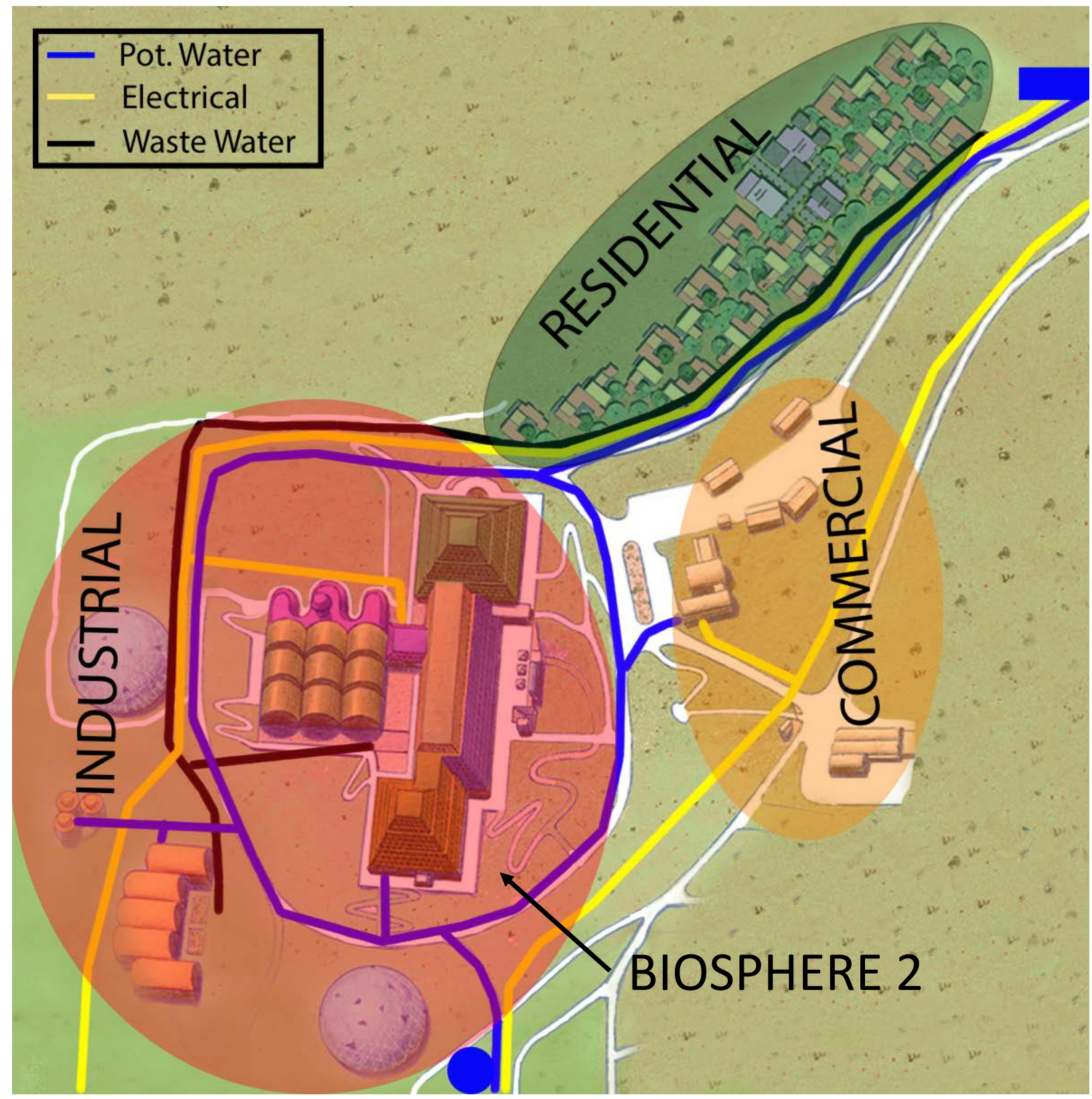

Figure 1. B2's energy and water infrastructure. Figure from University of Arizona staff

\subsection{Biosphere 2 Energy Systems}

The heart of the B2 facility is the Energy Center, which is responsible for the production of hot and cold air, heated and chilled water, and controlling power distribution and emergency power for seven model ecosystems. The Energy Center houses two backup generators, two boilers, and two chillers. This equipment is essential for maintaining air temperature, water flow, and air flow within the B2 environment. B2 itself has 26 air handling units (AHUs) used for temperature control and air circulation to meet biome requirements. While essential to meeting B2's operating parameters, this equipment also poses significant energy demands. 


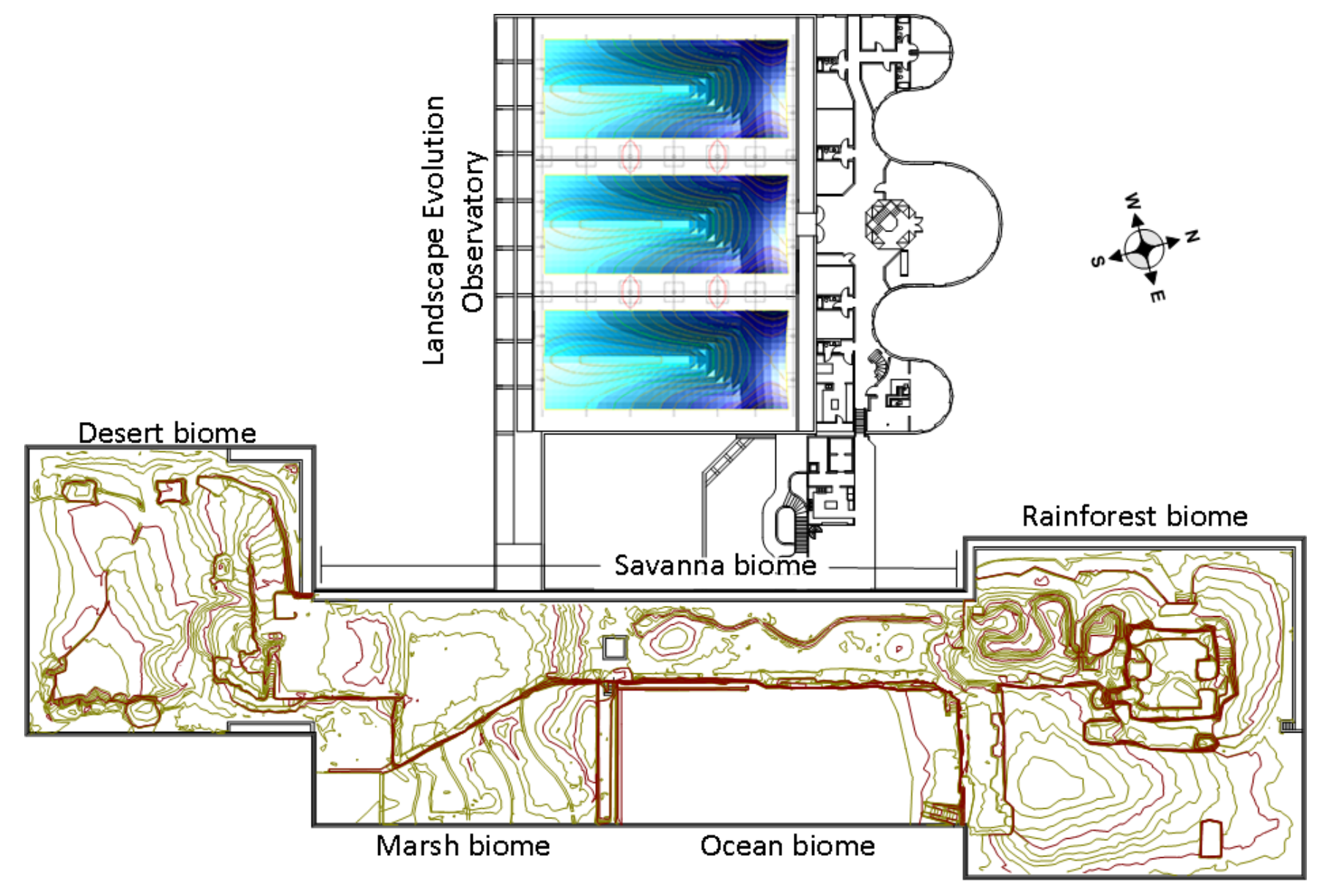

Figure 2. B2's model ecosystems. Figure from University of Arizona staff

\subsubsection{Electricity}

Electric power is provided to B2 by the San Carlos Irrigation Project (SCIP), a rural electric utility. The SCIP was authorized by an act of Congress in 1924 and is a Department of Interior, Bureau of Indian Affairs Agency, established to provide irrigation water to lands on the Gila River Reservation and certain lands adjacent to the reservation. SCIP purchases power from the Western Area Power Association and this power is transmitted over the Parker-Davis transmission system, also operated by Western Area Power Association, to the SCIP's three interconnection points. SCIP serves a peak load of about $80 \mathrm{MW}$, which occurs in summer and consumes $334 \mathrm{GWh}$ annually. The customer class split is approximately 35\% residential, 35\% commercial, 20\% industrial, and 10\% irrigation (SCIP 2012).

B2 is situated at the end of the SCIP's electrical transmission line. The site periodically experiences issues with power quality and outages, but overall the electricity supply is reliable. B2 has a small, 10kW SOLQuick PV array on site that operates parallel with the utility. The PV system provides power to the Conference Center and the Model Cities grid. While B2 does not currently generate more power on site than it consumes, SCIP does not currently allow net metering, which would be a consideration for establishing a microgrid at the site.

SCIP has four electrical feeds to the B2 site:

- Guard Shack

- Energy Center (B2)

- Main Site (Visitors Center and Casitas) 
- Water Pump.

B2 also has electrical sub-meters for each of the 28 Casitas, the Energy Center main import/export, and several other loads including the chiller, generators, and the guard gate (Figure 3).

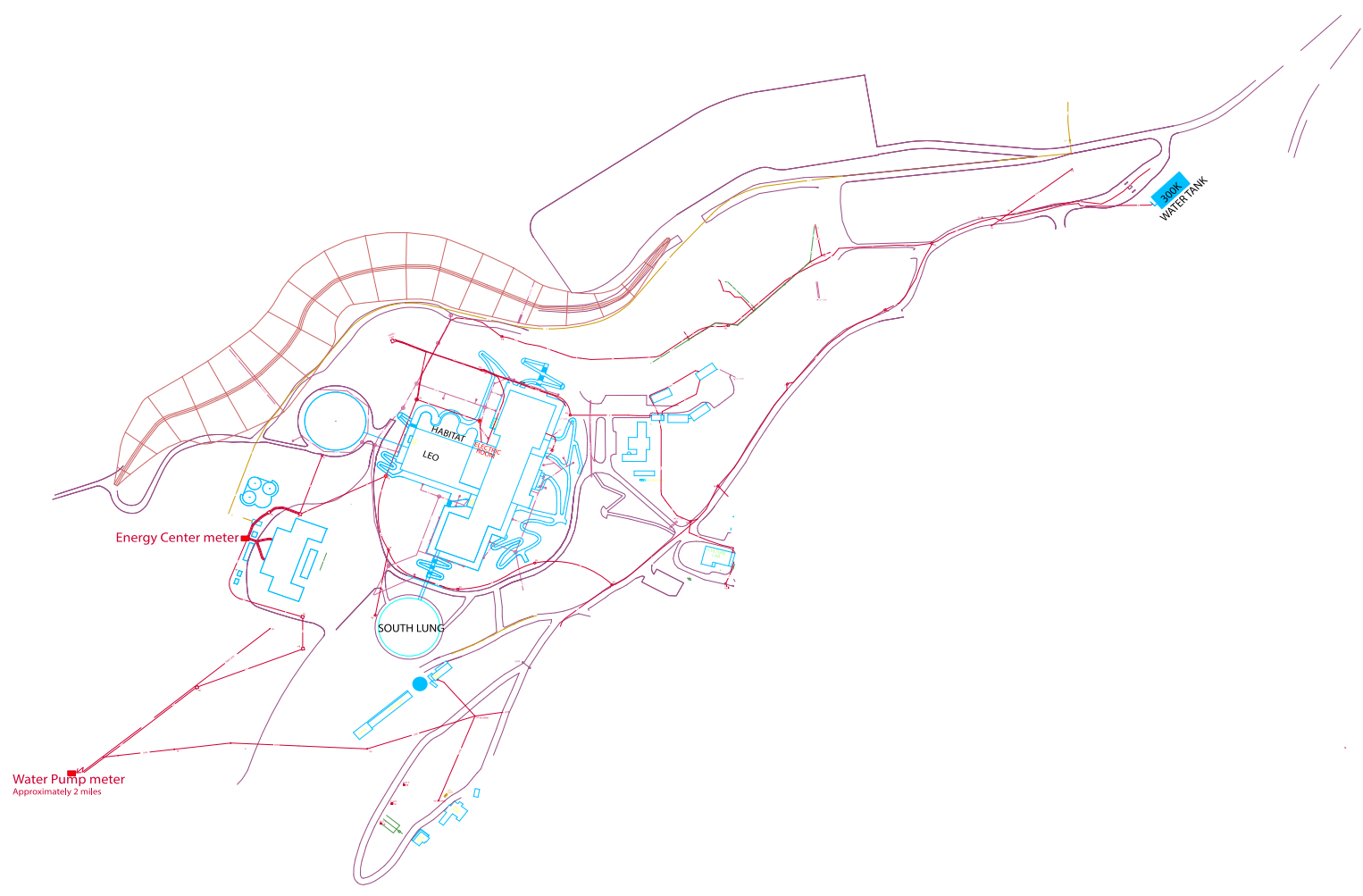

Figure 3. Campus facility map and electrical meter locations. Figure from University of Arizona staff

\subsubsection{Energy Center Electric Distribution System}

In this section we describe in detail the electric distribution system for the Energy Center, which accounts for more than $90 \%$ of the energy consumed in the B2 campus. The Energy Center is served by a $12.47 \mathrm{kV}$ line from SCIP to a B2-owned substation 3,750 kVA transformer that steps down the voltage to 4,160 V and feeds a parallel 4,160 V bus system (Bus A and Bus B) with 6 and 5 switches, respectively. Two switches from each bus provide three phase power to mechanically interlocked, parallel fused disconnect switches feeding two 4,160/480 V substations, but only one circuit from each 4,160 $\mathrm{V}$ bus is energized at any given time. The other two 4,160 V feeds are backup circuits. A third circuit from each 4,160 V bus feeds the chiller, and a fourth circuit serves the Energy Center loads and other B2 loads such as the cooling tower, fire pumps, and other auxiliary loads. The firth circuit from each bus is a spare and the extra circuit in Bus A serves the water storage tank pumps.

Both of the 4,160 V buses (Bus A and Bus B) are connected to the $1.5 \mathrm{MW}$ diesel generator and 1.5 MW natural gas generator. As such, if the main $12.47 \mathrm{kV}$ circuit feed to the $4,160 \mathrm{~V}$ bus system is lost, the generators can energize Bus A and Bus B circuits. Generators are synchronized by manual means: the operator manually adjusts the prime mover speed or the frequency control set point of the governor to match the generator frequency to the system frequency. Similarly, the operator manually adjusts the excitation level or voltage regulator set point of the exciter to match the generator voltage to the system 
voltage. The operator then initiates closing the breaker when the phase angle between the generator voltage and the system voltage is near 0 degrees.

The generators have frequency and voltage meters, frequency matching and synchronizing relays (relays American National Standards Institute (ANSI)/Institute of Electrical and Electronics Engineers (IEEE) Device 15 and 25 respectively). If used, the sync-check relay can back up the operator's decision to close the generator breaker. In other words, the sync-check device only allows breaker closure to occur when the phase angle, frequency, and voltage are within predetermined limits. The operator can close the breaker with added confidence knowing the sync check relay is double-checking the breaker closure.

The generation plants have an automatic synchronizer device that can perform all the functions required to synchronize a generator (providing control signals to the generator and exciter to match the frequency and voltage to the system and closing the breaker). However, the device is not programmed and not currently in use. Mechanical fatigue damage from small torsional disturbances caused by less-thanperfect synchronization is cumulative over time and can lead to early failure even if a faulty synchronization event never occurs. The improved consistency provided by an automatic synchronizer can limit the opportunity for this cumulative damage over the course of many synchronization events.

The power quality provided by the utility to the B2 site is not ideal. The 15-minute voltage profile in Figure 4 shows that there are several steady-state voltage violations. The red lines in Figure 4 denote the ANSI C84.1 limits Range A of acceptable service voltage. Power quality issues can either be caused by internal Energy Center loads or can come from the utility provider. As no time-series data was available for individual loads, these events could not be correlated with internal power draws.

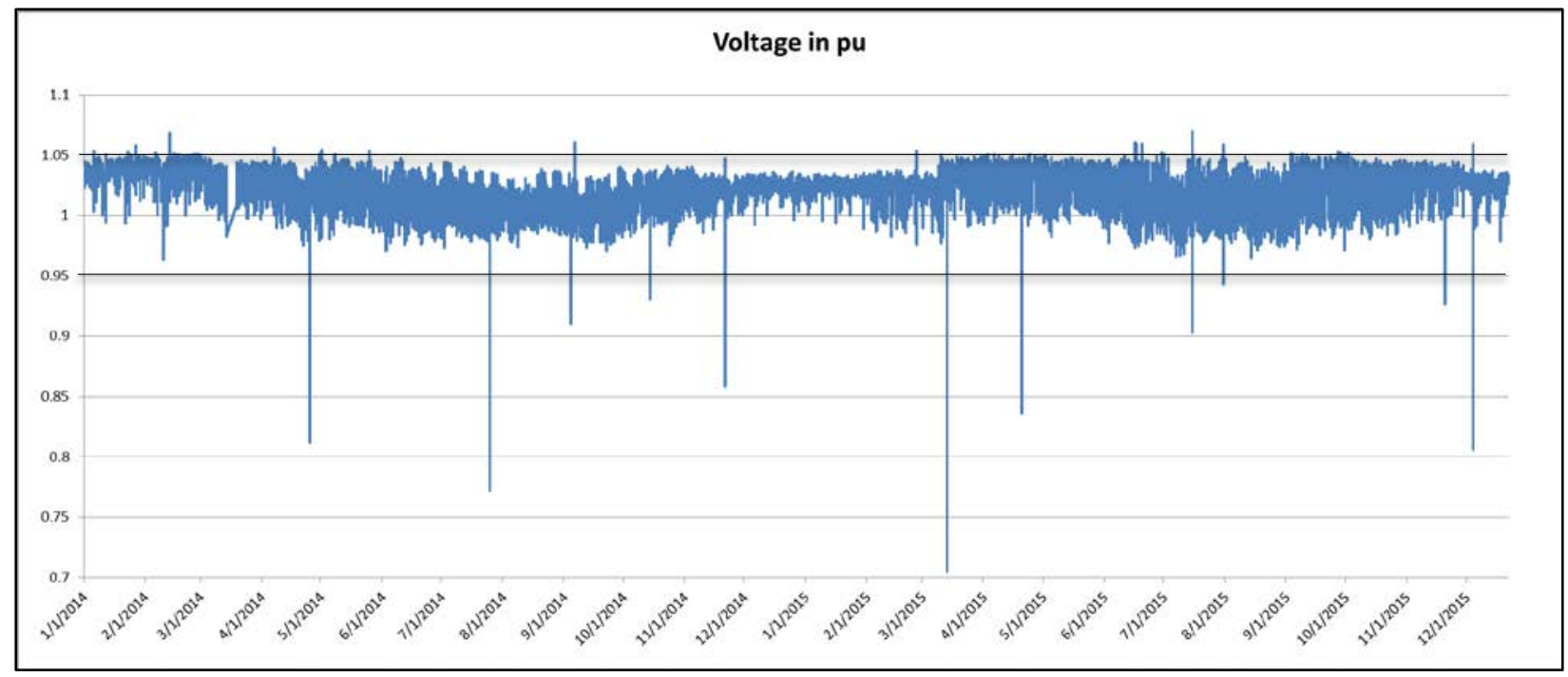

Figure 4. Voltage profile for 2014 and 2015

Note that currently the generators only serve the Energy Center loads but cannot be tied to the Main Site distribution system that serves the Visitors Center and the Casitas. For a future campus-wide microgrid, the Main Site feed would have to be tied with a new distribution line to the Energy Center distribution system. This flexibility to tie the Energy Center distribution system with the Main Site could also benefit from the integration of RE resources such as solar because a lot of the land available for PV would interconnect to the Main Site distribution system. 


\subsubsection{Electricity Consumption}

Of the four electrical feeds to the B2 site-Guard Shack, Energy Center (B2), Main Site (Visitors Center and Casitas), and Water Pump (Well) — the largest consumer is the Energy Center. A breakdown of electricity use by meter is found in Figure 5.

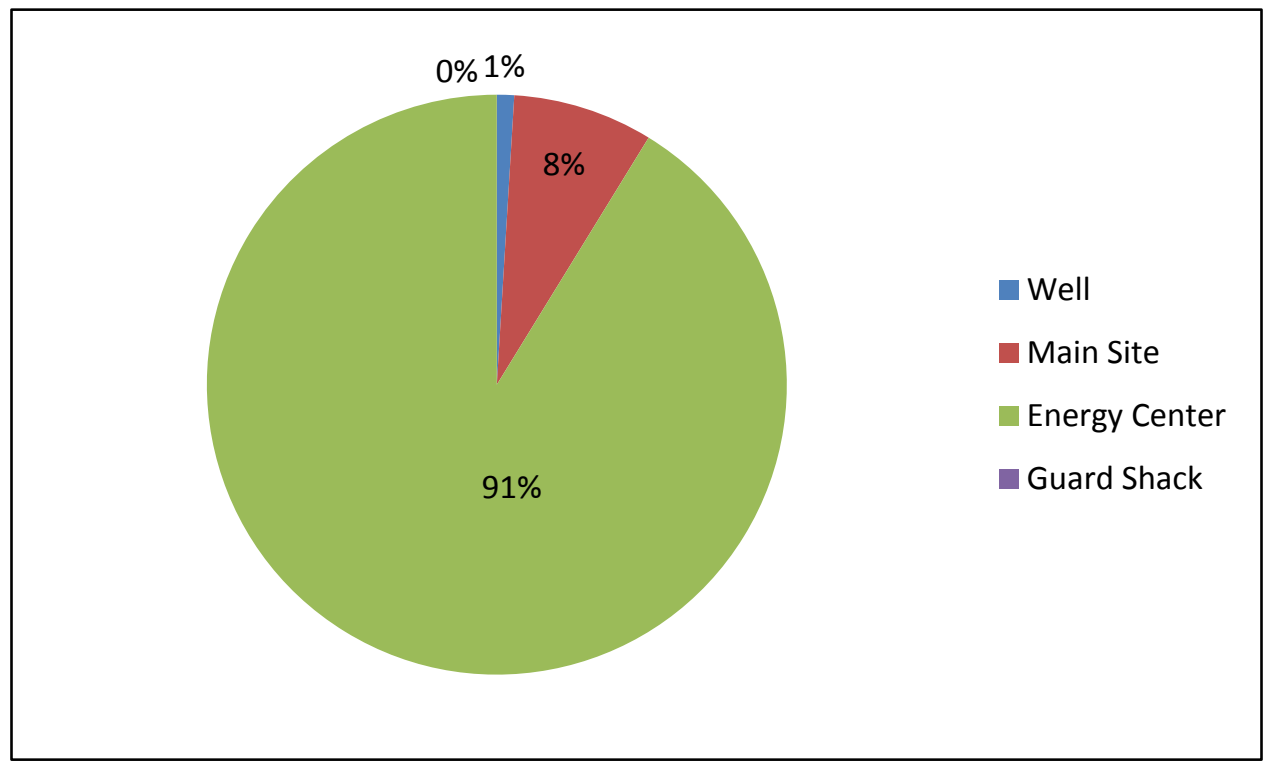

Figure 5. Percent electricity use by meter in $2015^{2}$

The Energy Center accounts for the most electricity use of the four meters (91\% of total electricity use on-site). Electricity use in the Energy Center has been increasing year after year, by an average of $4.9 \%$ per year, which can be seen in Figure 6. The largest load is for the chiller, which runs every night during summer months and for several hours every few days year-round. To the extent possible B2 relies on less energy intensive cooling towers to provide cooling in lieu of the chiller.

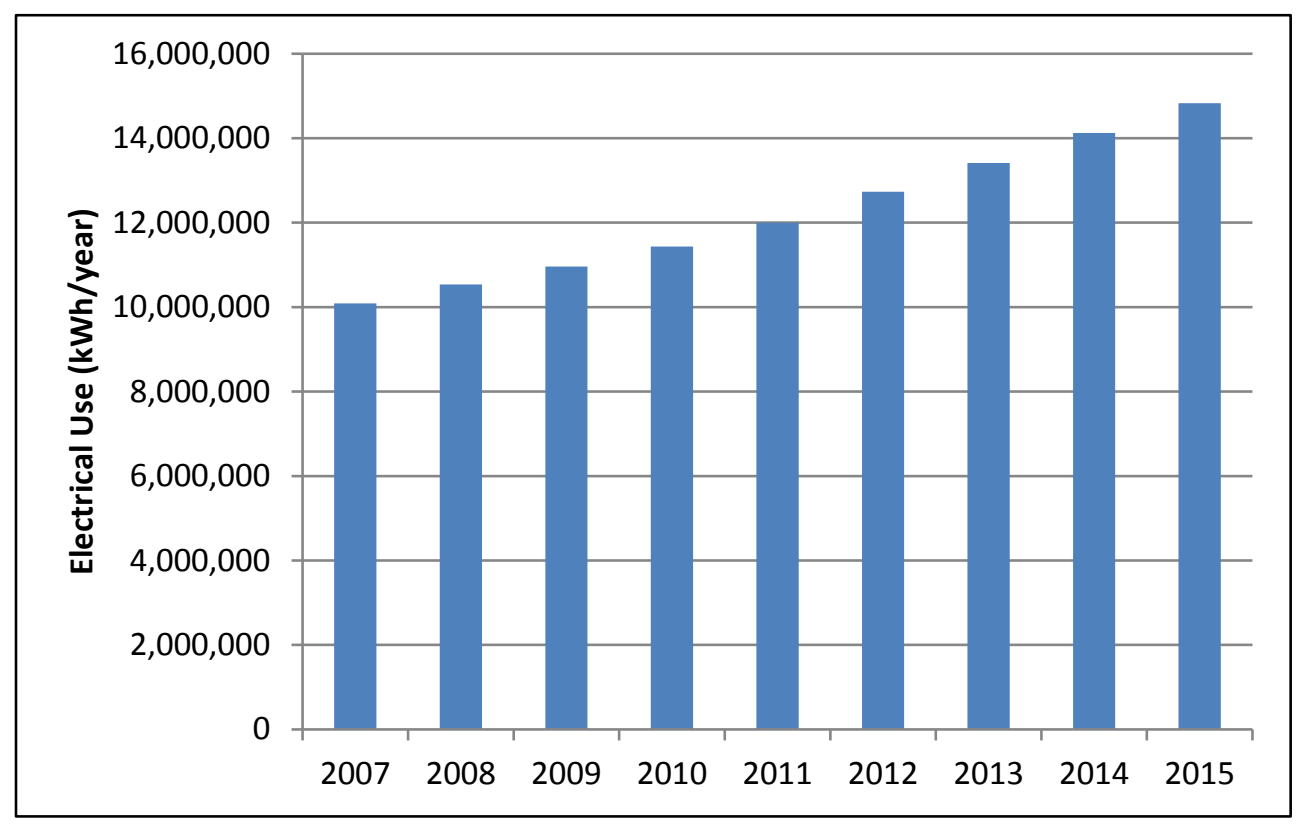

Figure 6. B2 Annual Energy Center usage from 2007-2015

\footnotetext{
${ }^{2}$ Energy use for the guard shack is negligible compared with other uses.
} 
The Energy Center electricity use is sub-metered and 15-minute load data are collected. The 2015 Energy Center load profile is shown in Figure 7. The maximum load in 2015 was $1.23 \mathrm{MW}$ and the minimum load was $105 \mathrm{~kW}$. The average monthly maximum and minimum loads are approximately 950 $\mathrm{kW}$ and $215 \mathrm{~kW}$ respectively.

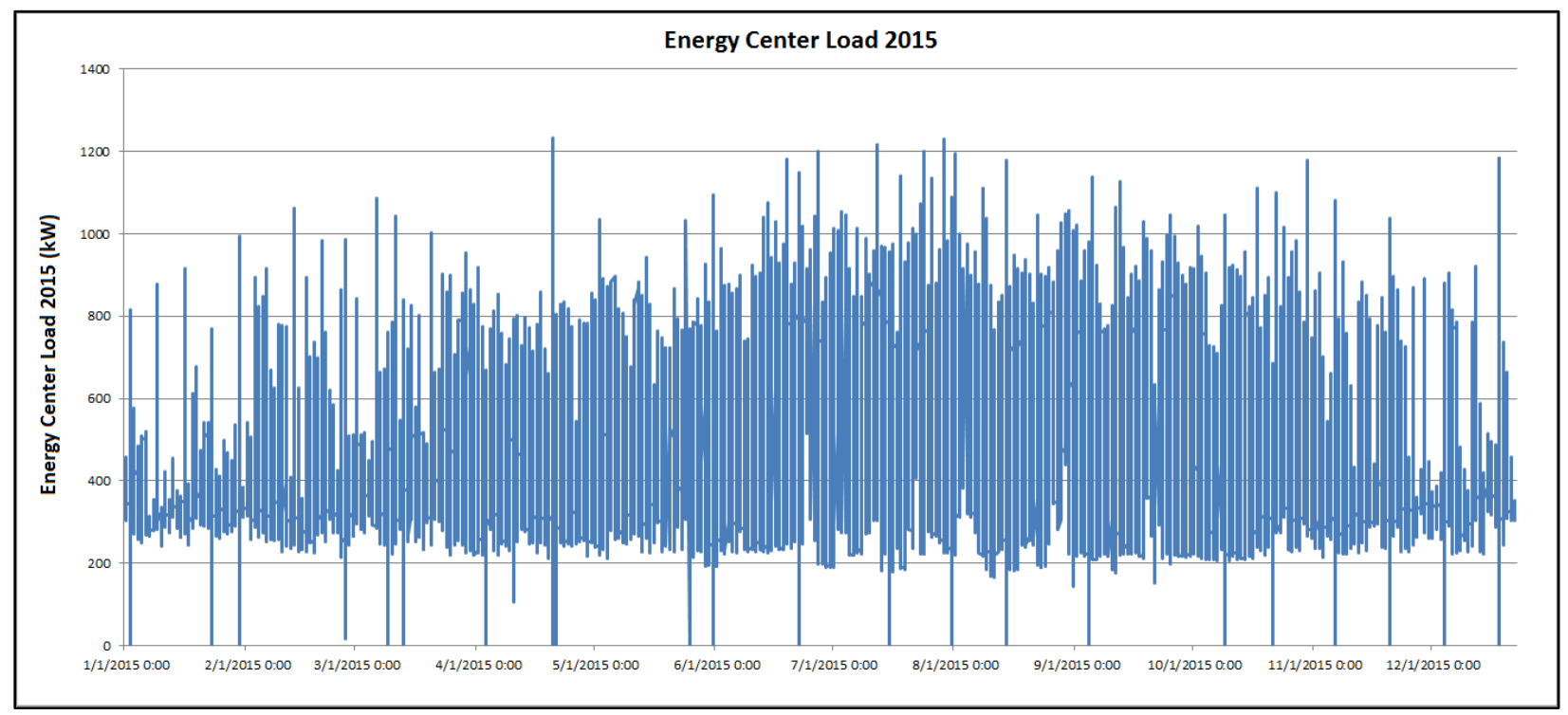

Figure 7. 2015 Energy Center load profile

The Casitas and the Visitor Center use about 8\% of total annual B2 electricity usage, and this use has also been increasing over time (averaging an increase of $8 \%$ per year), as seen in Figure 8.

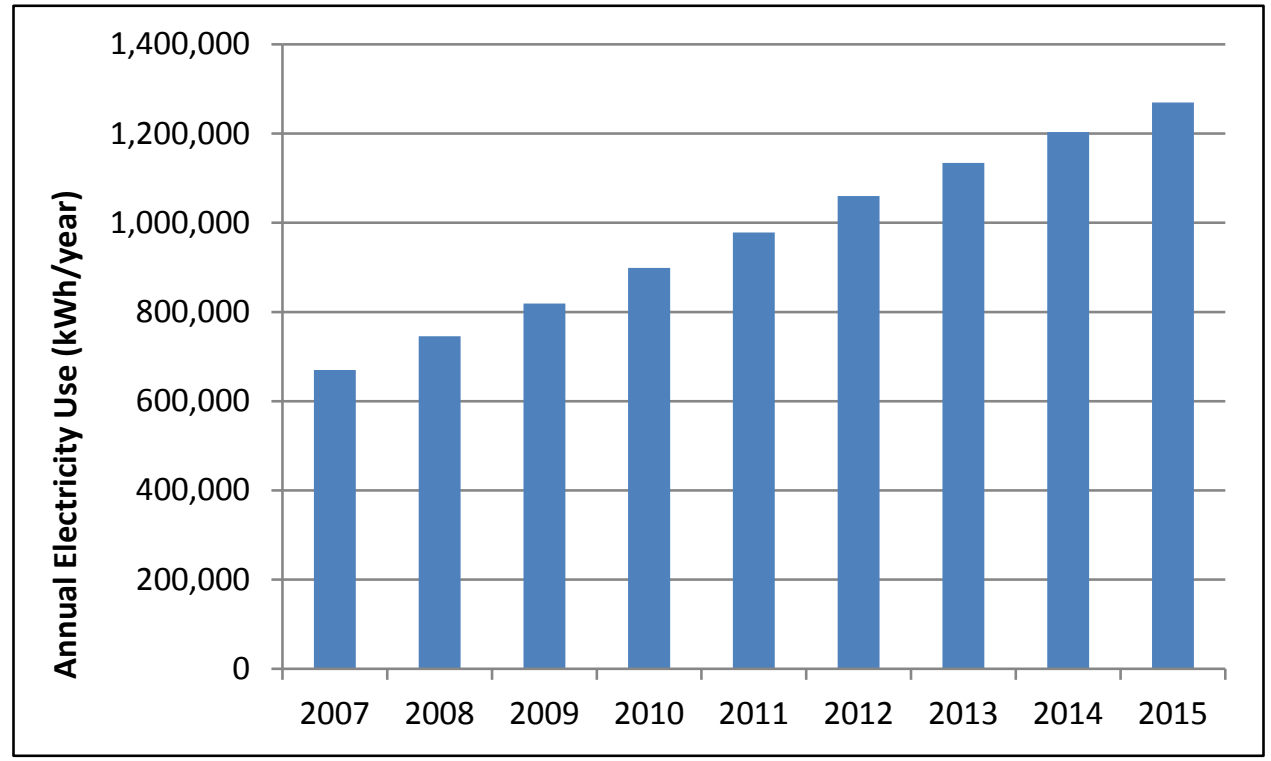

Figure 8. Casita and Visitor Center electricity usage from 2007-2015

\subsubsection{Energy Consumption for Water Systems}

Water is pumped uphill 500 feet to the B2 site and stored in an underground tank prior to distribution. Water is pumped as-needed based on the water level in two storage tanks. Pumps are turned on or off throughout the day, as required to maintain the water level in the tank. The wells represent a small portion (1\%-3\% historically) of B2's overall energy demand. To reduce energy use, variable frequency drives (VFDs) could be used to run the well pumps. Scheduling pumping to occur at off-peak hours 
could also result in peak demand electrical cost savings and would provide system flexibility to support microgrid operations. The annual electricity usage at the well, for pumping water from the well to the storage tanks, has decreased over time and now is only about $1 \%$ of the site's annual electricity usage, as seen in Figure 9.

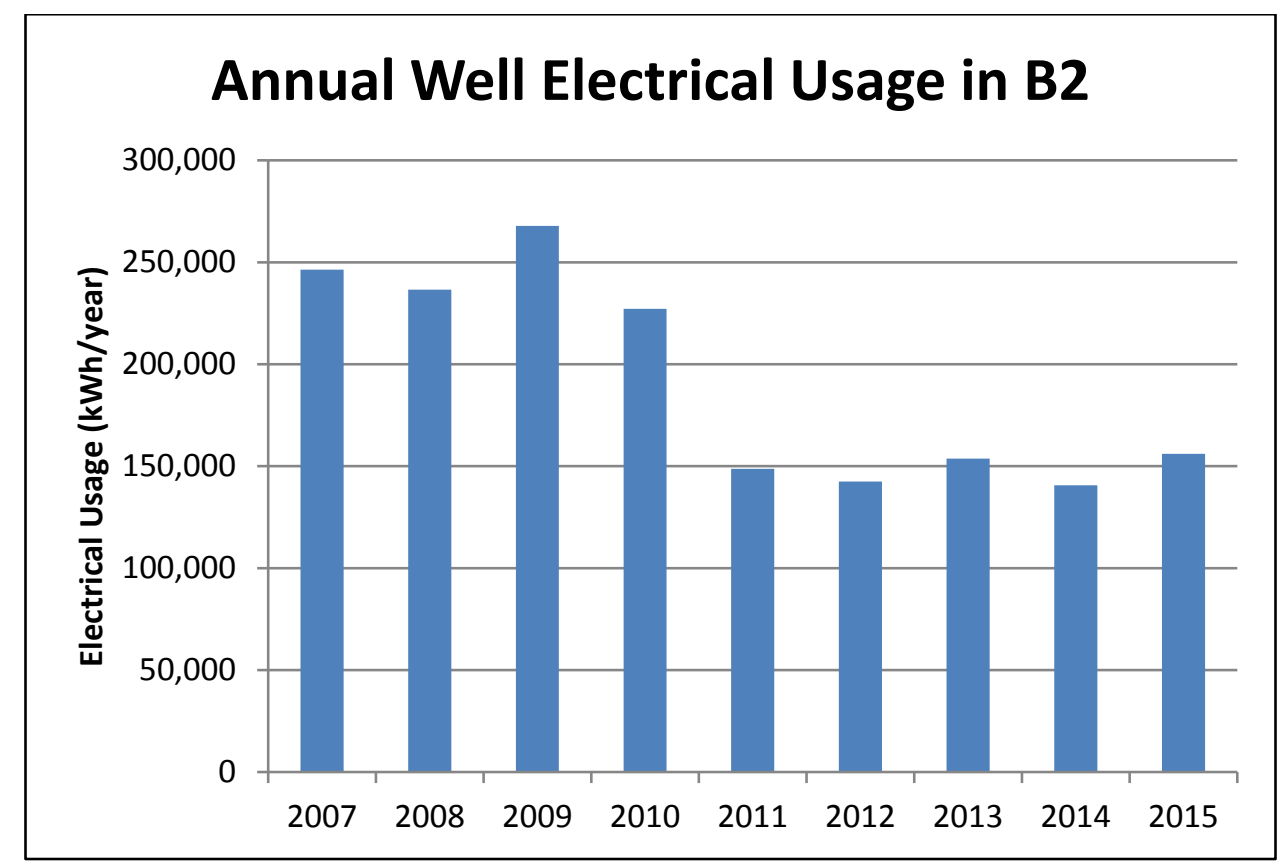

Figure 9. Annual Well electricity usage from 2007-2015

\subsubsection{Rate Structure for Electrical Systems}

As shown in Table 1, the Guard Shack and Water Pump meters are subject to the Small Commercial tariffs, while the Main Site and Energy Center meters are on the Large Commercial and Industrial electrical rates, respectively. The Guard Shack and the Water Pump are approximately $200 \mathrm{~W}$ and 100 $\mathrm{kW}$ loads, respectively, and are not included in this analysis. Given their significant energy demands, the microgrid analysis will focus on the Energy Center and Main Site loads.

Table 1. B2's Electricity Rate Structure

\begin{tabular}{lllll}
\hline \multicolumn{1}{c}{ Meters } & \multicolumn{1}{c}{ Rate } & \multicolumn{1}{c}{ Energy Charge } & $\begin{array}{c}\text { Demand } \\
\text { Charge }\end{array}$ & \multicolumn{1}{c}{ Minimum Bill } \\
\hline $\begin{array}{l}\text { Guard Shack, } \\
\text { Water Pump }\end{array}$ & $\begin{array}{l}\text { Small } \\
\text { Commercial }\end{array}$ & $\begin{array}{l}\$ 0.13 / \mathrm{kWh} \text { for the next } 950 \mathrm{kWh} \\
\$ 0.080 / \mathrm{kWh} \text { for the next } 9,000 \mathrm{kWh} \\
\$ 0.060 / \mathrm{kWh} \text { for all energy }\end{array}$ & $\$ 2.00 / \mathrm{kW}$ & $\begin{array}{l}\$ 20.00 \text { per month. } \\
\text { Includes the first } 50 \mathrm{kWh} \\
\text { of energy used in a month }\end{array}$ \\
\hline Main Site & $\begin{array}{l}\text { Large } \\
\text { Commercial }\end{array}$ & $\begin{array}{l}\$ 0.095 / \mathrm{kWh} \text { for the next } 10,000 \mathrm{kWh} \\
\$ 0.065 / \mathrm{kWh} \text { for all energy }\end{array}$ & $\$ 3.00 / \mathrm{kW}$ & $\begin{array}{l}\$ 50.00 \text { per month. } \\
\text { Includes the first } 500 \mathrm{kWh} \\
\text { of energy used in a month }\end{array}$ \\
\hline Energy Center & Industrial & $\$ 0.050 / \mathrm{kWh}$ for all $\mathrm{kWh}$ & $\$ 7.00 / \mathrm{kW}$ & $\$ 250.00$ per month \\
\hline
\end{tabular}

\subsubsection{Natural Gas}

Natural gas is provided by Southwest Gas with an approximate cost of \$1.26/therm. B2 natural gas use is presented in Figure 10. There are two gas meters feeding the Energy Center and no additional submetering of natural gas consumption. Natural gas use is primarily attributed to the two, 10 million $\mathrm{Btu} /$ hour natural gas fired hot water boilers and one 1.5 MW natural gas backup generator. 


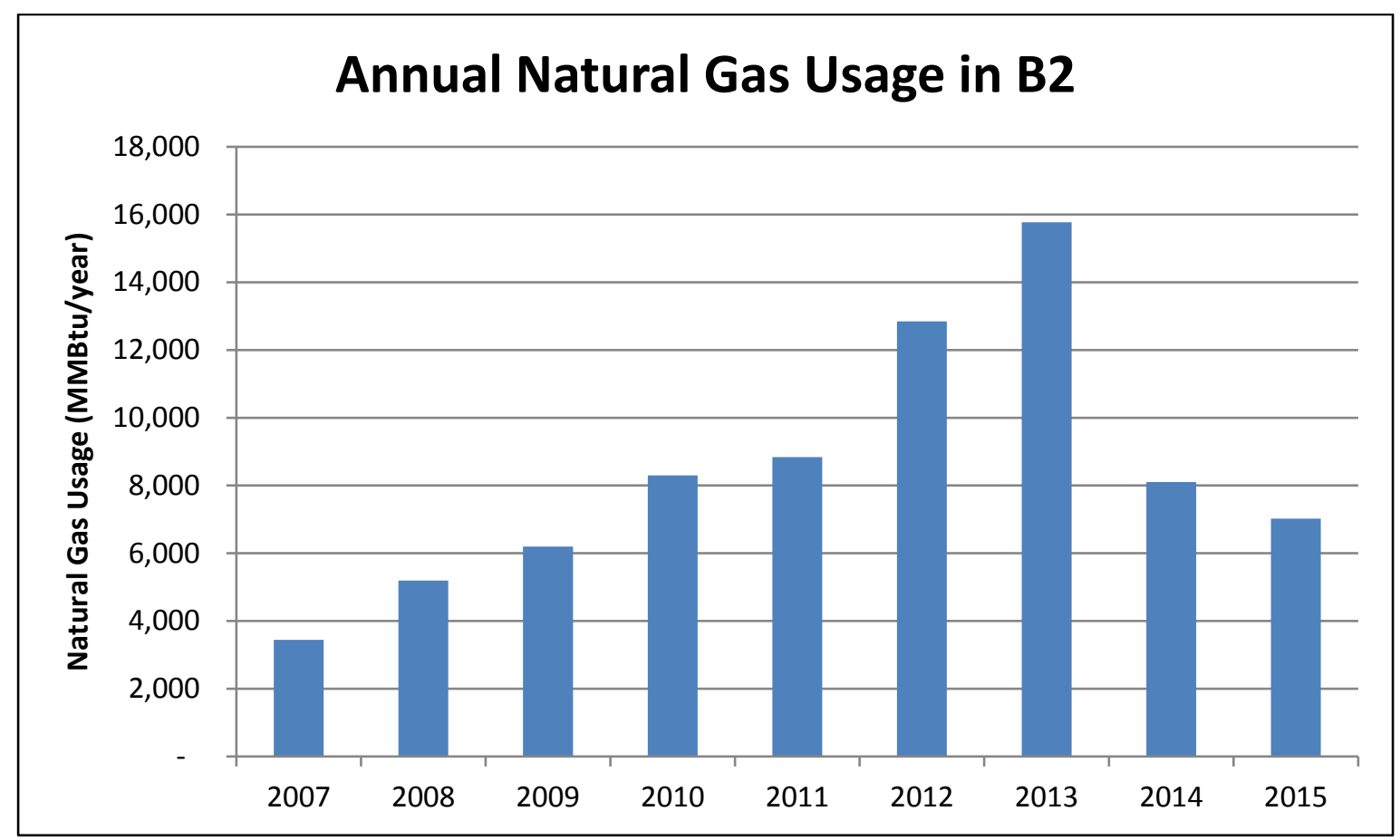

Figure 10. Annual natural gas usage from 2007-2015

\subsubsection{Energy Systems Operating Parameters}

Occupant comfort, health, and safety are the primary drivers for B2's operating practices and associated energy loads. Biome temperature and humidity are other key drivers. B2's science advisor group also works with researchers to determine what changes can be made to the Biosphere's experiments.

Typically, modifications are made to temperature and humidity levels in the biomes to support research objectives. The Biosphere facility does not exceed $80^{\circ} \mathrm{F}$ for comfort and safety purposes. Nighttime energy loads are significantly lower than daytime loads. Maximum cooling typically occurs between 7:00 a.m. and 5:00 p.m. when B2 is open to the public and hosting visitors. Chilled water is maintained between $44^{\circ}$ and $56^{\circ} \mathrm{F}$ as the most optimal range.

When there is a power outage B2 operations staff manually start the diesel generator to power critical loads, resulting in a blackout of typically fewer than 15 minutes depending on how quickly an operator can respond. Figure 11 shows an outage that occurred on April 17, 2012, sometime between 6:00 p.m. and 6:15 p.m., and lasted for at least 3 hours and 15 minutes. The site was without power for approximately 30 minutes until the diesel generator was manually started up sometime between 6:30 p.m. and 6:45 p.m. In this case, only the diesel generator was run. 


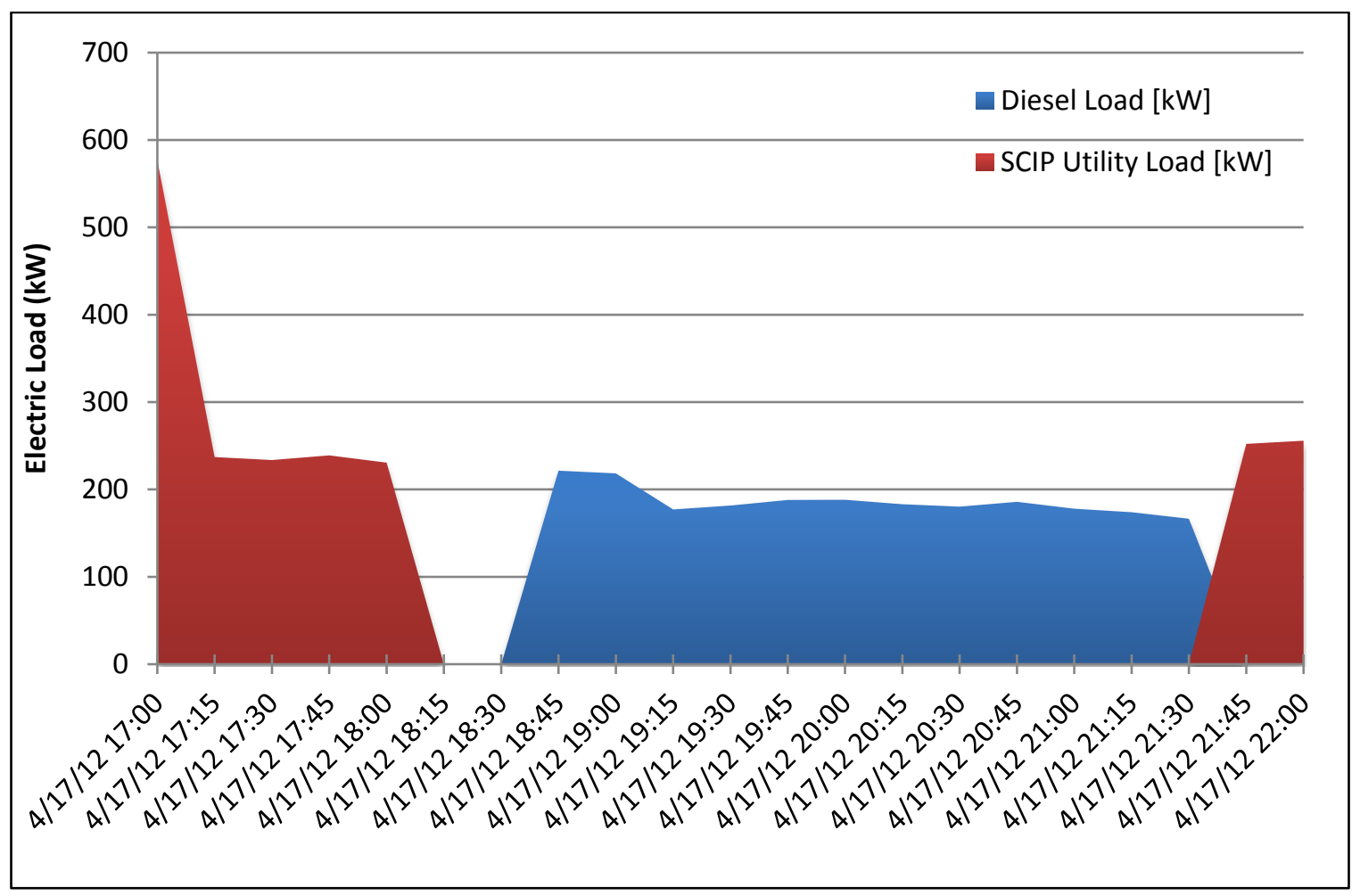

Figure 11. April 18, 2012, from 5-10 p.m., Energy Center and B2 load (SCIP) and diesel generator load

In case of a power outage, most of B2's cooling equipment turns off and has to be started up again through the control system. Some equipment must be manually reset to start back up after an outage (for example, pump controllers), and as such it takes approximately 30 to 45 minutes to return to normal operations after an outage. The site has ten 3,000-gallon diesel storage tanks. This storage could power the diesel engine for approximately two weeks. Typically, the diesel is started first because it ramps up faster and can better pick up large load transients, and then the load is transferred to the natural gas generator for the remainder of the outage.

B2 also has an Uninterruptable Power Supply system that can power critical loads for 30 minutes and improve the power quality to the critical loads during normal operation. Critical loads include the control racks in each biome, the wave generator, the laser equipment, and the server room. The Energy Center has its own small Uninterruptable Power Supply system that supports the control system servers.

\subsubsection{System Controls}

The control system or industrial automation system for the main equipment at the Biosphere and Energy Control Center is conducted through National Instruments field modules integrated with Allen-Bradley 5/40E Programmable Logic Controllers. The Human Machine Interface (HMI) is also built using the National Instruments Lookout v5, which allows historical data viewing and management capabilities. The main load control functions performed by the current automation system are for temperature, humidity, and irrigation at the Biosphere's biomes. In addition, the HMI visualizes the B2 owned substation and 4,160 V double bus system where the natural gas and diesel generators are connected.

All the control functions for the main equipment are performed manually from the Energy Center based on operator experience. The control system previously had more sophisticated controls (e.g., PID control for AHUs), but currently all the controls are manual from the HMI. 


\subsection{Biosphere 2 Water Systems}

\subsubsection{Water Sources and Infrastructure}

The B2 site is fed by two groundwater wells, which provide 100 acre-feet of water from CDO Ventures. The water used on the B2 site is gifted by CDO Ventures in an agreement that will be renegotiated in 2019. All water infrastructure on the B2 site is owned by B2. B2 has a non-community, non-transient water system that serves fewer than 100 people. B2 is currently reevaluating its water supply options because of a potential Domestic Water Improvement District that CDO Ventures will be involved with for a new residential development nearby. B2 has additional groundwater resources, which B2 could potentially use by drilling their own well(s) and installing additional distribution piping, pumping, and storage infrastructure.

The B2 has two water meters:

- Well Site

- Cooling Tower Makeup.

B2 has the following water storage infrastructure:

- 7,000-gallon well tank

- 7,000-gallon B2 Research Development Complex tank

- 200,000-gallon tank

- 300,000-gallon tank.

B2 also has an on-site wastewater treatment plant that serves all but three Casitas, which rely on a septic system. Wastewater is discharged to a holding tank and then to an on-site bog for natural infiltration. The Biosphere facility's wastewater is also discharged to a septic system. The wastewater treatment plant is sized to accommodate 100 to 1,000 gallons per day, based on the number of visitors and Casita occupancy. B2 is required to stay under 28,000 to 30,000 gallons per month of sewage discharge.

\subsubsection{Water Consumption}

Water consumption at B2 is dominated by water use for the cooling tower, biome irrigation, and humidity requirements. Other water uses include domestic use, fire suppression (stored in one of the Biosphere’s “lungs”), and irrigation. Annual water consumption data can be seen in Figure 12. 


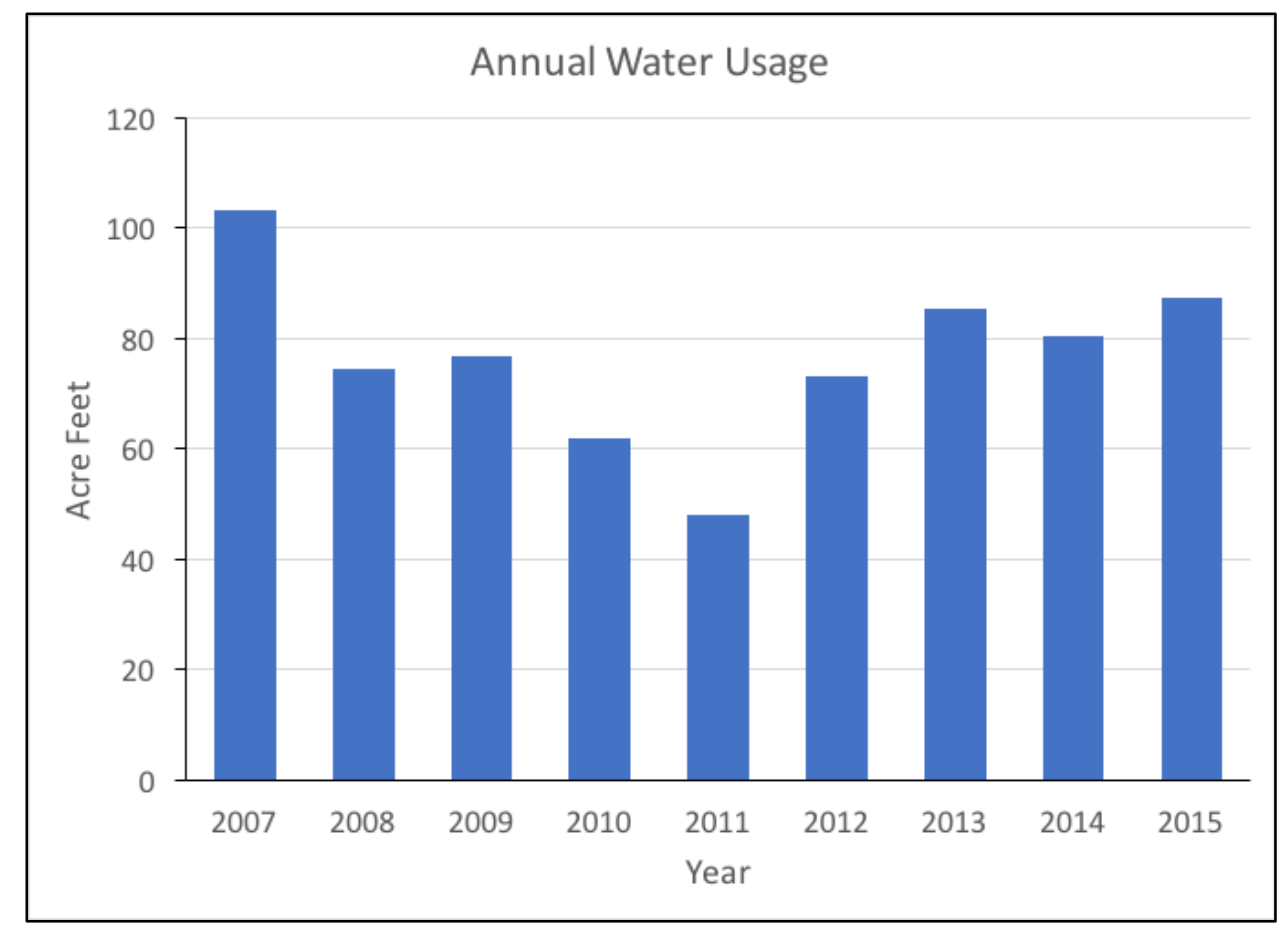

Figure 12. Annual water consumption from 2007-2015

\subsubsection{Water Consumption for Energy Systems}

The largest water consuming energy system in B2 is the cooling tower, in the form of makeup water. B2's cooling tower is used to provide cooling to the Biosphere's facilities and biomes. B2's cooling tower is rated at 23 million Btu/hour, has a water flow rate of 4,240 gallons per minute (gpm) and an evaporation rate to reject $23.3 \times 10^{6} \mathrm{Btu}$ heat/hour of $47 \mathrm{gpm}$. The gallons of makeup water used in B2 from 2007 through 2015 are presented in Figure 13.

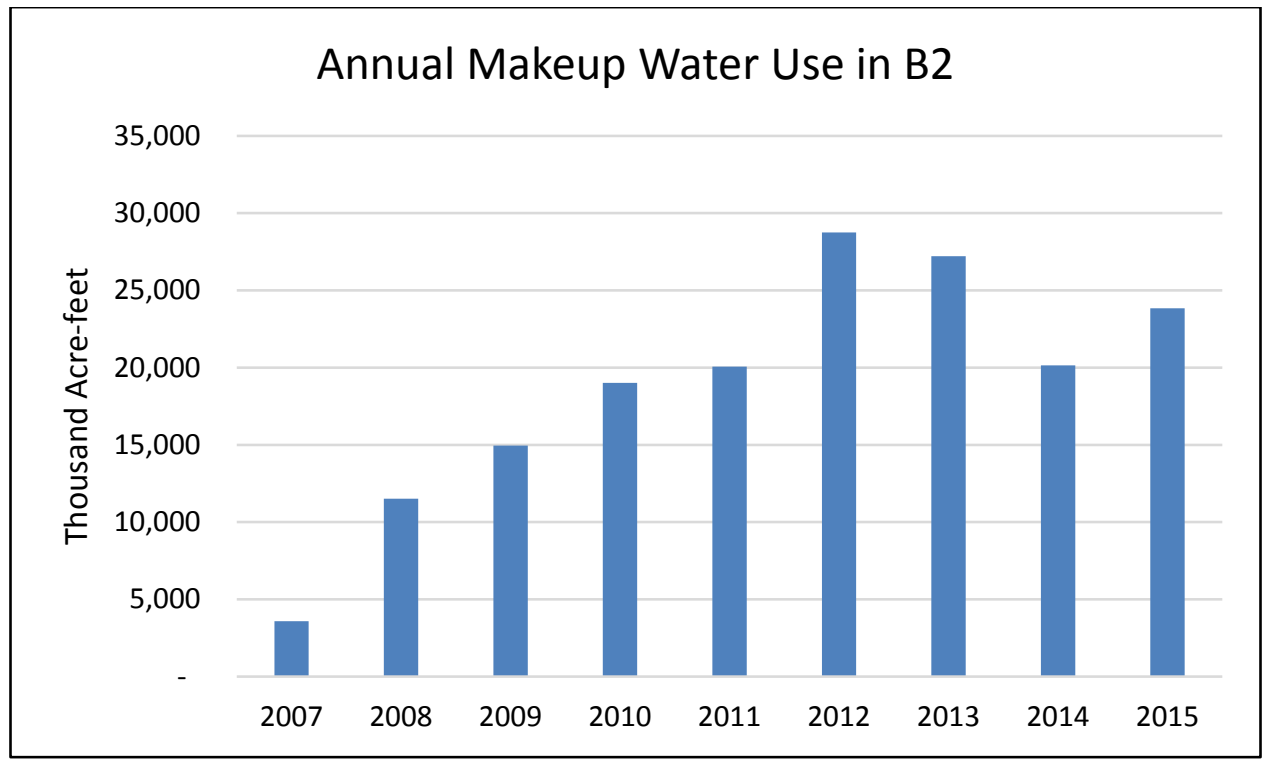

Figure 13. Annual makeup water usage from 2007-2015

\subsubsection{Water Rate Structure}

Water is currently supplied at no cost to B2 from CDO Ventures. B2 is only responsible for paying electricity to pump water and for a person to perform maintenance and water quality testing. 


\subsubsection{Water System Operating Parameters}

Once groundwater reaches the B2 site it is stored in two tanks (totaling 500,000 gallons of storage), which provide ample volume to meet operational needs. Water flows by gravity from the tanks to the B2 facilities. Standard operating practice is to keep both tanks almost full. Water at B2 receives water softening pretreatment and RO. Ultraviolet disinfection treatment is also used to prevent algal blooms. Ocean water receives additional dosing of highly concentrated sea salt to maintain the biome's requirements. All biome water systems are physically separated to prevent any cross contamination.

Water use at B2 is driven by experiments, biome requirements, and human comfort needs. All biomes have a regular rainfall schedule, which varies based on experimental and habitat-specific needs. Water quality is also adjusted based on biome needs. 


\section{Energy-Water Microgrid Conceptual Design at Biosphere 2}

The B2 facility has unique characteristics that make it a favorable location for an energy-water microgrid demonstration, including:

- Large dispatchable loads: B2 has large energy loads that have the potential to be used as a dispatchable resource, flexibility in water system operations, and sufficient back-up generators to support microgrid operations.

- Onsite generation: The site has a 1.5 MW diesel generator and a 1.5 MW natural gas generator that can support B2 and Energy Center loads throughout an outage. B2 is located in an area with a great solar resource and significant available land area to add RE and/or storage systems.

- Microcosm of other potential sites for microgrids: The B2 facility is in a remote location at the end of the electrical distribution system and relies on well water for its potable water supply. The site has periodic issues with power reliability and quality, and thus has motivation to explore potential islanding of their electric system. B2 has also demonstrated operations independent from the grid using their back-up generators for up to 10 days.

- Diverse industrial, commercial, and residential loads: B2 accommodates a range of loads to support research functions, tours and educational activities, and visiting researchers.

- Educational and public outreach focus: A component of the mission of B2 is education and outreach to industry, government, and the public, as well as lessons learned and best practices from this demonstration that can be broadly disseminated through outreach programs. Further, the B2 facility is an ideal test bed for demonstrating and promoting the viability of highly efficient closed-loop systems that integrate RE, water, and food/land resources.

The following sections describe the foundational components of developing an energy-water microgrid at the B2 facility along with preliminary analyses of optimal system configurations.

\subsection{Optimization and Efficiency Opportunities}

Prior to establishing a microgrid at the B2 facility, efforts should be made to increase efficiency and optimize B2's energy and water system operations. During the site visit and from review of B2 data, the following opportunities were identified and should be considered prior to pursuing a microgrid.

- Implement VFDs where applicable to improve energy efficiency of motors used in B2 operations and reduce spikes in electricity demand that occur when starting motors. VFDs will also be important for a future microgrid as systems that are inverter dominated, such as RE and battery systems, may have difficulty handling large inrush currents of motor or compressor loads.

- Implement demand-side management strategies, including adjusting scheduling and adding controls to optimize operation of energy and water systems.

- $\quad$ Reduce Biosphere facility energy use by adding insulation, replacing windows, and replacing inefficient motors and equipment. B2 has many operable windows, which could be used for ventilation (at certain times of year) in lieu of energy intensive AHUs.

- Implement more sophisticated PID controller control loops for equipment (and windows) in lieu of manual HMI activation to optimize energy use.

- Dissipate heat more efficiently to shed heat loads using louvers/operable windows in desert and rainforest in lieu of AHUs. 
- Ramp cooling/heating load during early and late portion of the day when internal climate requirements could be efficiently met through VFD control or modular heating systems.

- Integrate on-site RE (PV, wind), batteries, and excess water storage into daily operations.

- Implement water conservation strategies (e.g., new cooling tower water treatment approach to reduce make-up water needs).

\subsection{Available Energy Resources}

\section{Solar}

PV can be an effective technology to offset energy demand and supplement demand management. The B2 site has a very good solar resource $\left(6.48 \mathrm{kWh} / \mathrm{m}^{2} /\right.$ day). For comparison, one of the best locations for solar resource in the country is in Phoenix, Arizona, $\left(6.57 \mathrm{kWh} / \mathrm{m}^{2} /\right.$ day) and one of the worst is in Buffalo, New York, (3.99 kWh/m²/day).

B2 has significant land areas that could potentially host PV systems, such as the ridge and the land behind the Energy Center. U of A has been exploring the potential to deploy PV on their property, including $200 \mathrm{~kW}$ on the lawn and $800 \mathrm{~kW}$ on a carport structure in the parking lot.

B2 currently does not have any solar thermal systems installed; however, opportunities exist for solar hot water use to meet hot water loads at the Casitas and for heating the ocean.

\section{Wind}

Previous wind assessments indicated that the wind resource was not strong at B2 and would not be a viable RE option. Adjacent U.S. Forest Service land may have a good wind resource, which could be explored further.

\section{Backup Generators}

The site's 1.5 MW diesel and 1.5 MW natural gas back-up generators currently supply emergency power in the case of an electricity supply outage. These generators were not considered in the analysis as the focus of the analysis was to understand the feasibility of renewable powered microgrid operations for a scenario of fuel supply disruption, but could be used for load demand reduction or primary energy supply in microgrid operations

\section{Hydropower}

The B2 site has changes in elevation that could support the deployment of small scale hydropower generation. Water could be pumped from the wells to a storage tank(s) at a higher elevation (when there is excess electricity or when electricity rates are lowest), and then released and run through a turbine to generate electricity when needed. The configuration of tanks with excess volume and water flowing by gravity on the B2 site could also be explored further for energy storage possibilities. The potential for this would need to be studied in more detail.

\section{Load Flexibility}

B2 loads have some potential flexibility, and operations could be shifted to avoid peak demand charges (e.g., pump water from wells, moving water from tanks, irrigation, storage tank recharge, cooling tower blowdown/make-up, chiller operation).

\subsection{Microgrid Design and Performance}

This analysis includes a preliminary RE microgrid design for the B2 Energy Center to show the level of $\mathrm{RE}$ generation and storage a 100\% RE-powered microgrid would require, assuming the microgrid would 
meet 35\% of the current Energy Center load. Remaining load would be reduced through energy efficiency and demand-side management strategies or shed as noncritical during an outage. It was assumed that the existing conventional generation assets would not be used as part of this microgrid, to simulate a microgrid that could power B2 under conditions where fuel is not available (such as during an extended outage where fuel supply is disrupted). Table 2 shows the assumptions used in the analysis.

Table 2. Microgrid Modeling Assumptions ${ }^{3}$

\begin{tabular}{|l|l|}
\hline Variable & Value \\
\hline Electric utility cost escalation rate & $0.1 \%$ \\
\hline Inflation rate & $0.1 \%$ \\
\hline Analysis period & 10 years \\
\hline Ownership model & Direct ownership \\
\hline Discount rate & $3.1 \%$ \\
\hline Incentives & None \\
\hline PV cost & $\$ 2.00 / \mathrm{W}$ \\
\hline Battery cost & $\$ 675 / \mathrm{kW}+\$ 425 / \mathrm{kWh}$ \\
\hline Critical load & $\begin{array}{l}35 \% \text { of typical load; } 2014 \\
\text { load data used in analysis }\end{array}$ \\
\hline
\end{tabular}

Modeling results show that to power 35\% of the Energy Center load with only RE, B2 will require approximately 2.3 MW of PV and a 9.8 MWh, 0.9 MW battery. This system would have an initial cost of $\$ 9.3$ million, and a net present value (NPV) of $-\$ 6.4$ million. This means B2 would pay a premium of $\$ 6.4$ million over the 10 -year life ${ }^{4}$ of the system to power their critical loads with PV and storage, compared to what they would have paid if they had continued to purchase electricity from the utility. Note that the costs presented here include only the PV and battery system. All equipment is assumed to have lifetimes equal to or greater than the 10-year analysis period. The cost of isolating critical loads on a critical load panel, an automatic transfer switch, and a microgrid controller would be additional and are not included. The system sizes and economics are summarized in Table 3.

Table 3. Renewable Energy Microgrid System Sizes and Economics

\begin{tabular}{|l|l|}
\hline \multicolumn{2}{|c|}{ System Size and Energy Production } \\
\hline PV Size & $2,279 \mathrm{~kW}$ \\
\hline Battery Size & $9,793 \mathrm{kWh} ; 877 \mathrm{~kW}$ \\
\hline Electricity Produced & $\begin{array}{l}3,613,744 \mathrm{kWh} / \text { year } \\
(75 \% \text { of total site load) }\end{array}$ \\
\hline \multicolumn{2}{|c|}{ System Economics } \\
\hline PV Capital Cost & $\$ 4,558,000$ \\
\hline Battery Capital Cost & $\$ 4,754,000$ \\
\hline Total Capital Cost & $\$ 9,312,000$ \\
\hline Annual O\&M & $\$ 45,580 /$ year \\
\hline $\begin{array}{l}\text { Base Case Lifecycle Cost } \\
\text { (LCC) }\end{array}$ & $\$ 2,798,016$ \\
\hline PV/Storage Case LCC & $\$ 9,201,984$ \\
\hline NPV & $-\$ 6,403,968$ \\
\hline Simple Payback & 24.1 years \\
\hline
\end{tabular}

\footnotetext{
${ }^{3}$ Source of assumptions include B2 data, NREL standard assumptions, and (Anderson et al. 2017).

${ }^{4}$ A 10-year analysis period was used because of standard University of Arizona contracting requirements, which may negatively impact economic outcomes as compared to a more typical 25-year analysis period.
} 
Figure 14 shows an example of how the PV and storage would be dispatched to meet critical loads for one week in February. In this week, there are three days in a row of marginal solar resource where the 2.3 MW PV system is producing only about $10 \%$ of its capacity. During this period, only $35 \%$ of the total load is met. On sunnier days, there is some excess PV generation above the critical load. On these days, the excess generation could be used to meet noncritical loads or could be curtailed. It is more economically advantageous to build a relatively larger PV system and smaller battery, even if it means sometimes curtailing PV generation.

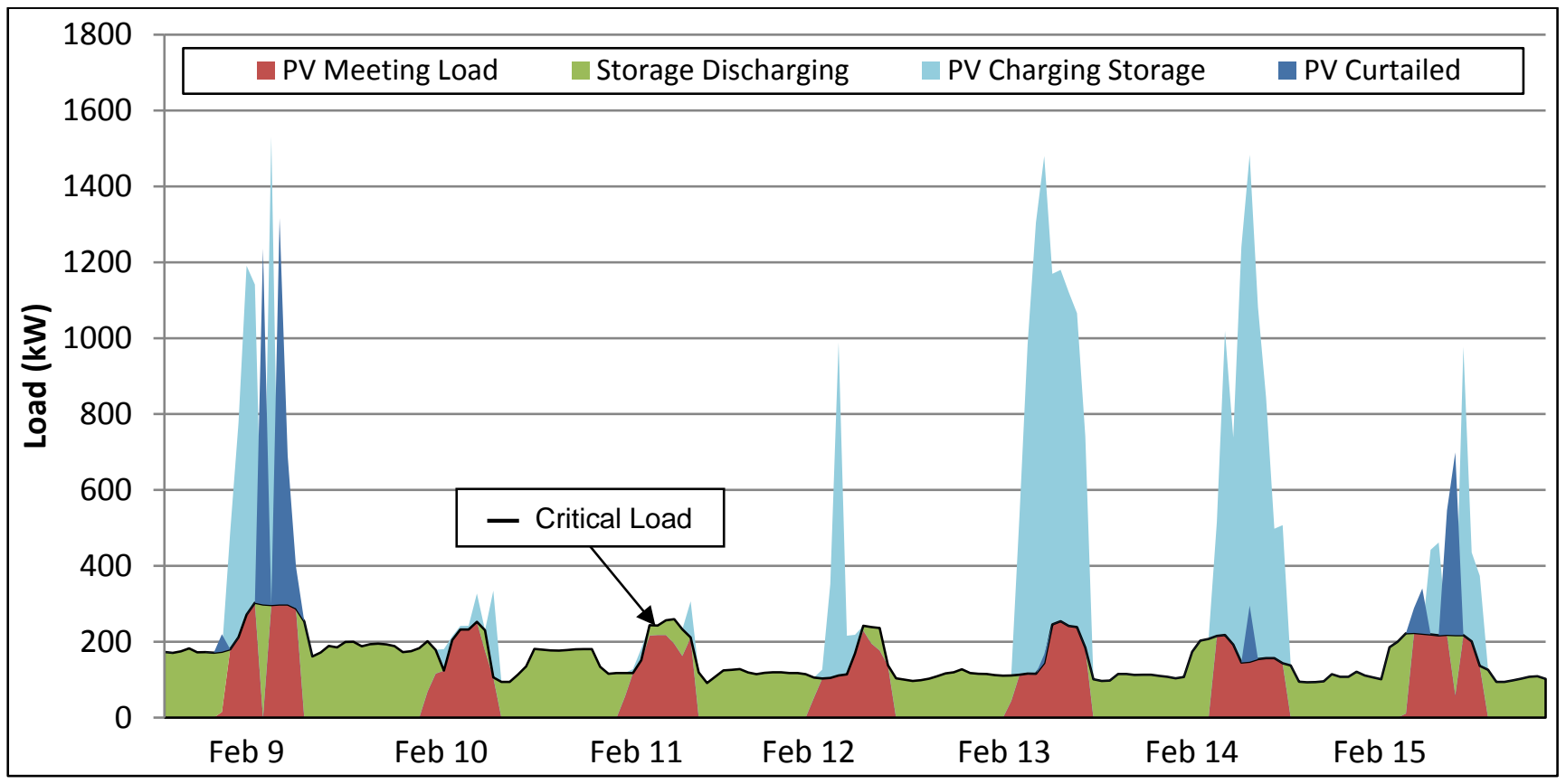

Figure 14. PV and storage sustain the critical load in the $100 \%$ renewable energy microgrid

Alternatively, if demand management or alternate generation sources can be used to reduce load during peak load days or days of poor solar resource, a smaller PV and battery system may suffice. For example, if we allow the model to include a diesel generator and use up to 3,000 gallons of diesel fuel per year for 10 years (the site currently has ten 3,000-gallon fuel tanks), the required system sizes to sustain the critical load indefinitely are reduced. The PV system size is reduced by $12 \%$ to $2.0 \mathrm{MW}$. The battery capacity is reduced $47 \%$ to $5.2 \mathrm{MWh}$ and the battery power is reduced $22 \%$ to $0.7 \mathrm{MW}$. Because a smaller PV system and battery are required, the initial cost is reduced by $26 \%$ to $\$ 6.9$ million, and the NPV is $-\$ 4.0$ million (a \$2.4 million lifecycle savings compared to the RE-only microgrid). The system sizes and economics for the PV/diesel/storage hybrid microgrid are summarized in Table 4. 
Table 4. Renewable Energy + Diesel Microgrid System Sizes and Economics

\begin{tabular}{|l|l|}
\hline \multicolumn{2}{|c|}{ System Size and Energy Production } \\
\hline PV Size & $2,015 \mathrm{~kW}$ \\
\hline Battery Size & $5,209 \mathrm{kWh} ; 685 \mathrm{~kW}$ \\
\hline Diesel Generator & $192 \mathrm{~kW}$ \\
\hline Electricity Produced & $3,195,862 \mathrm{kWh} /$ year \\
\hline \multicolumn{2}{|c|}{ System Economics } \\
\hline PV Capital Cost & $\$ 4,030,000$ \\
\hline Battery Capital Cost & $\$ 2,676,200$ \\
\hline Generator Capital Cost & $\$ 188,528$ \\
\hline Total Capital Cost & $\$ 6,894,728$ \\
\hline Annual O\&M & $\$ 40,300 /$ year \\
\hline Base Case LCC & $\$ 2,798,016$ \\
\hline PV/Storage Case LCC & $\$ 6,830,973$ \\
\hline NPV & $-\$ 4,032,957$ \\
\hline Simple Payback & 18.3 years \\
\hline
\end{tabular}

While not included in this analysis, future work could evaluate the opportunity to use dispatchable loads and water storage to further reduce the size and cost of the PV and battery storage systems required to sustain the critical loads. In addition, it would also be recommended to enhance the Energy Management System to have full microgrid control type capabilities for high-level dispatch and lower-level DER optimization and control. Additional system integration and control costs for large campuses can be in the range of $\$ 750-\$ 1,500$.

\subsection{Microgrid Data Acquisition and Control System}

The microgrid system should be designed with a sophisticated energy-related data acquisition system, so that the same system is used to optimize daily energy uses and support the research experiments with an advance control platform.

A modernized data acquisition and control infrastructure with a microgrid controller capable of controlling both conventional and RE generation sources can:

- Monitor and control DER

- Balance supply and demand

- Optimize resources and load

- Transition between island and parallel states

- Respond to utility or market demand response dispatch.

\subsection{Limitations of Analysis}

This study is intended to provide the foundation for a detailed feasibility assessment for a microgrid at the B2 facility. A full feasibility assessment would include higher resolution data and modeling activities to fully verify initial estimates. Some key limitations of this work that could be improved upon in future studies are outlined here:

- Hourly timesteps of energy usage and generation data were used in the analysis. Smaller timesteps would be needed in future analyses that design a system to address scenarios where the net load is dynamic, or in scenarios where PV is a significant contributor of power. 
- No consideration in this analysis was given to thermal loads or thermal storage opportunities. Chilled storage tanks could be used to smooth the electric load profile and/or to provide ridethrough during loss of supply, while hot water storage tanks could be used to smooth the natural gas load profile and/or provide ride through during loss of supply. A chilled water tank could also directly prevent having to curtail PV (and is aligned well with the cooling load), while the hot water tank could do the same with the integration of supplemental electric hot water heating. Future analyses may want to consider the addition of thermal loads and resources.

- This analysis did not include an assessment of the ability of the system to maintain system voltages and frequencies within limits when operating in a microgrid model. More detailed power system models would be required as part of a microgrid development process.

- Future analyses should consider the ability of the optimal power generation mix to meet the specific demands of critical loads, such as inrush currents associated with starting compressors. 


\section{Opportunities for Future Collaborative Research}

While initial analyses show promising potential and opportunities of an energy-water microgrid at the B2 facility, there remain substantial research gaps and opportunities for collaborative research to more comprehensively understand tradeoffs and configurations of different microgrid designs. Specific opportunities are discussed in this section.

\section{Economic analyses}

Additional analytical efforts are needed to more fully assess the economic benefits and tradeoffs associated with developing an energy-water microgrid at B2, and the potential implications for future microgrid developments in other areas. Key questions and remaining gaps include consideration of costs associated with battery degradation, variability in reliability and cost of current grid connections, how technology advancements could affect economic, long-term maintenance and sustainability given current B2 water and energy equipment, expansion of B2 research activities and the resulting changes in energy and water loads, opportunities for B2 to generate excess electricity or provide grid services, and potential financial incentives to improve the financial viability of a microgrid.

\section{Controls and optimization}

Successful operation of the B2 facility for research and human comfort purposes requires creating conditions that balance the oftentimes competing requirements of individual biomes, made more complex by the interaction with external ambient temperatures. There is significant room for improvement in the optimization of B2 conditions through the addition and increased use of controls and automated systems. The use of automated systems would allow for a more energy- and water-efficient B2, while also providing the flexibility needed for microgrid operations. Additional data are needed to fully characterize flows of energy and water throughout the B2 facility, better understand the interactions among the biomes within B2, experiment with alternative operational protocols, conduct scenario analysis under a variety of extreme conditions and design a control system and user interface that could be implemented at the B2 facility. Sub-meters and data loggers could be beneficial in helping document how energy and water systems are being operated and how these operations could be modified to support a microgrid environment.

\section{Water systems}

While a small percentage of overall site energy use, the water systems at B2 are worthy of further exploration for their potential to support microgrid operations. In this vein, there is a need to further study the feasibility of using the water tanks as energy storage. Efforts to reduce water use in the cooling towers by increasing cycles of concentration would also help improve the efficiency of water use on site. Improving metering and data collection on water system operations, as well as including duration, frequency of use, and associated energy implications, would also help inform a robust strategy for a future microgrid at B2.

\section{Cybersecurity and resilience}

Cybersecurity is a growing concern for both power and water systems, with the threat of data theft and operational disruptions demanding the need for greater system security and resilience. Cybersecurity threats remain an understudied field for microgrids, and the B2 facility could serve as a primary test bed for detecting, addressing, and preventing cybersecurity impacts on these systems. These research activities could include software vulnerability detection advancements, cybersecurity architecture and protocol development, cybersecurity training, cybersecurity roadmap development, and cybersecurity evaluation and simulation at the B2 facility. 


\section{Solar resource forecasting and installation configuration}

PV technologies would likely be the RE technology selected to power the energy-water microgrid at B2, and there are several key research gaps that would need to be addressed to fully understand how it could be integrated into the microgrid. In particular, there would need to be additional research on solar resource forecasting techniques for the region and a better understanding of the variability of the solar resource at multiple temporal scales. In addition, future efforts will need to better identify ideal locations for PV infrastructure, which could include evaluation of various types of vegetation that could be located underneath the panels.

\section{Partnerships with regional electric utilities}

Given the potential for the B2 facility to island itself from the grid but also to generate additional electricity or provide grid services, greater interaction and collaboration with regional electric utilities will be needed to better understand the value of the services that B2 could provide in the context of what regional electricity utilities need. Discussions with SCIP and Tucson Electric Power could lead to additional insights into optimal configurations of the microgrid that could benefit not only the B2 campus but also the integrity and resilience of the broader electric grid. Future efforts could also quantify the economic and security value of B2 operating as a microgrid. 


\section{Conclusions}

Moving toward an advanced energy-water microgrid that can incorporate effective energy management systems and smart load shedding schemes could help improve the daily energy performance and water management at the B2 site. Enabling such a microgrid system would create a holistic energy and water optimization system that would provide electricity to critical loads within the microgrid, and would improve power quality, flexibility, and reliability by integrating various sources of energy.

Here we provide an overview of the B2 system and identify an effective way to integrate RE into a microgrid system. By using renewable generation and energy storage strategies, the B2 site can decrease fuel inventories, add redundant energy sources, and reduce the microgrid carbon footprint. The mix of existing conventional generators combined with RE and storage provides a greater degree of flexibility to the system while assisting with the integration of renewable components as well.

When energy generation and storage (virtual storage from managing water and electrical loads) are distributed, reliability is generally improved. The more sources of electricity generation that are available across the site, the less likely it is for a disruption to impair site operations.

We provide a targeted list of research priorities that could be pursued to more fully understand the tradeoffs and benefits of an energy-water microgrid at the B2 facility, which could serve as a roadmap going forward to implement a microgrid. 


\section{References}

Amarasinghe, P., Liu, A., Egodawatta, P., Barnes, P., McGree, J., and Goonetilleke, A. 2016.

"Quantitative assessment of resilience of a water supply system under rainfall reduction due to climate change." J Hydrol 540:1043-1052. doi: 10.1016/j.jhydrol.2016.07.021

Anderson, K. H., Cutler, D. S., Olis, D. R., Elgqvist, E. M., Li, X., Laws, N. D., DiOrio, N. A., and Walker, H. A. 2017. "REopt: A Platform for Energy System Integration and Optimization." National Renewable Energy Lab. (NREL), Golden, CO (United States)

Bazilian, M., Rogner, H., Howells, M., Hermann, S., Arent, D., Gielen, D., Steduto, P., Mueller, A., Komor, P., Tol, R. S. J., and Yumkella, K. K. 2011. "Considering the energy, water and food nexus: Towards an integrated modelling approach." Energy Policy 39:7896-7906. doi:

10.1016/j.enpol.2011.09.039

Bognar, K., Pohl, R., and Behrendt, F. 2012. "Seawater reverse osmosis (SWRO) as deferrable load in micro grids, Desalination and Water Treatment." 51:4-6, 1190-1199, doi:

10.1080/19443994.2012.715093

Cendoya, M. G., Toccaceli, G. M., Battaiotto, P. E., and Vignoni, R. J. 2015. "Microgrid for remote areas with Water Pumping, based on wind-diesel DER and Energy Storage." 2015 IEEE PES Innovative Smart Grid Technologies Latin America (ISGT LATAM). pp 154-159

Deng, Y., Cardin, M-A., Babovic, V., Santhanakrishnan, D., Schmitter, P., and Meshgi, A. 2013.

"Valuing flexibilities in the design of urban water management systems." Water Res 47:7162-7174. doi: 10.1016/j.watres.2013.09.064

Diao, K., Sweetapple, C., Farmani, R., Fu, G., Ward, S., and Butler, D. 2016. "Global resilience analysis of water distribution systems." Water Res 106:383-393. doi: 10.1016/j.watres.2016.10.011

Falco, G.J. and Webb, W. R. 2015. "Water Microgrids: The Future of Water Infrastructure Resilience." Procedia Eng 118:50-57. doi: 10.1016/j.proeng.2015.08.403

Haritza, C., Octavian, C., Aitor, E., Alvaro, L., and Amélie, H. P. 2016. "Research experimental platforms to study microgrids issues." Int J Interact Des Manuf IJIDeM 10:59-71. doi: 10.1007/s12008015-0288-X

Hussey, K. and Pittock, J. 2012. "The Energy-Water Nexus: Managing the Links between Energy and Water for a Sustainable Future." Ecol Soc 17:. doi: 10.5751/ES-04641-170131

Hwang, H., Forrester, A., and Lansey, K. 2014. "Decentralized Water Reuse: Regional Water Supply System Resilience Benefits." Procedia Eng 70:853-856. doi: 10.1016/j.proeng.2014.02.093

Lasseter, R.H. and Paigi, P. 2004. "Microgrid: a conceptual solution." 2004 IEEE 35th Annual Power Electronics Specialists Conference (IEEE Cat. No.04CH37551). p 4285-4290 Vol.6

Macknick, J., Zhou, E., O’Connel, M., Ibanez, E., and Hummon, M. 2016. "Water and Climate Impacts on Power System Operations: The Importance of Cooling Systems and Demand Response Measures." NREL (National Renewable Energy Laboratory (NREL), Golden, CO (United States)) 
Mbarga, A. A., Song, L., Ross Williams, W., and Rainwater, K. 2014. "Integration of Renewable Energy Technologies With Desalination." Curr Sustain Energy Rep 1:11-18. doi: 10.1007/s40518-0130002-1

Piratla, K. R. and Goverdhanam, D. 2015. "Decentralized Water Systems for Sustainable and Reliable Supply." Procedia Eng 118:720-726. doi: 10.1016/j.proeng.2015.08.506

Plappally, A. K. and Lienhard V, J. H. 2012. "Energy requirements for water production, treatment, end use, reclamation, and disposal." Renew Sustain Energy Rev 16:4818-4848. doi:

10.1016/j.rser.2012.05.022

Sanders, K. T. 2015. "Critical Review: Uncharted Waters? The Future of the Electricity-Water Nexus." Environ Sci Technol 49:51-66. doi: 10.1021/es504293b

Sanders, K. T. and Webber, M. E. 2012. "Evaluating the energy consumed for water use in the United States." Environ Res Lett 7:034034. doi: 10.1088/1748-9326/7/3/034034

San Carlos Irrigation Project. 2012. Integrated Resource Plan. https://www.wapa.gov/EnergyServices/Documents/SCIP2012.pdf

Sitzenfrei, R., Möderl, M., and Rauch, W. 2013. "Assessing the impact of transitions from centralised to decentralised water solutions on existing infrastructures - Integrated city-scale analysis with VIBe." Water Res 47:7251-7263. doi: 10.1016/j.watres.2013.10.038

Ton, D. T. and Smith, M. A. 2012. "The US Department of Energy’s microgrid initiative." Electr J 25:84-94

Watts, G., von Christierson, B., Hannaford, J., and Lonsdale, K. 2012. "Testing the resilience of water supply systems to long droughts." J Hydrol 414-415:255-267. doi: 10.1016/j.jhydrol.2011.10.038 